\title{
Article
}

\section{The impact of membrane lipid composition on antimicrobial function of an $\alpha$-helical peptide}

Dennison, Sarah Rachel, Morton, Leslie Hugh Glyn, Harris, Frederick and Phoenix, David Andrew

Available at http://clok.uclan.ac.uk/7629/

Dennison, Sarah Rachel ORCID: 0000-0003-4863-9607, Morton, Leslie Hugh Glyn, Harris, Frederick and Phoenix, David Andrew (2008) The impact of membrane lipid composition on antimicrobial function of an $\alpha$-helical peptide. Chemistry and Physics of Lipids, 151 (2). pp. 92-102. ISSN 00093084

It is advisable to refer to the publisher's version if you intend to cite from the work. http://dx.doi.org/10.1016/j.chemphyslip.2007.10.007

For more information about UCLan's research in this area go to http://www.uclan.ac.uk/researchgroups/ and search for <name of research Group>.

For information about Research generally at UCLan please go to http://www.uclan.ac.uk/research/

All outputs in CLoK are protected by Intellectual Property Rights law, including Copyright law. Copyright, IPR and Moral Rights for the works on this site are retained by the individual authors and/or other copyright owners. Terms and conditions for use of this material are defined in the policies page.

\section{CLoK}

Central Lancashire online Knowledge www.clok.uclan.ac.uk

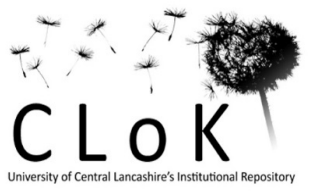




\title{
The impact of membrane lipid composition on antimicrobial function of an a-helical peptide
}

\author{
Sarah R Dennison ${ }^{\mathrm{a}}$, Leslie. H. G. Morton ${ }^{\mathrm{b}}$, Frederick Harris ${ }^{\mathrm{b}}$ and David A Phoenix ${ }^{\mathrm{a}^{*}}$ \\ ${ }^{a}$ Faculty of Science and Technology, University of Central Lancashire, Preston PR1 2HE, UK \\ ${ }^{\mathrm{b}}$ Department of Forensic and Investigative Science, University of Central Lancashire, \\ Preston, PR1 2HE, UK.
}

*Corresponding author:

Prof. David Phoenix,

Dean's Office,

Faculty of Science and Technology

University of Central Lancashire,

Preston, PR1 2HE, UK.

Tel: 01772 893481; Fax: 01772894964

E-Mail: daphoenix@uclan.ac.uk

Abbreviations: $\alpha$, interaction parameter; $\Delta \mathrm{H}$, mixing enthalpy; $\mathrm{CL}$, Cardiolipin; $\mathrm{Cs}^{-1}$, Compressibility modulus; DOPE, Dioleoylphosphatidylethanolamine; DOPG, Dioleoylphosphatidylglycerol; FTIR, Fourier transform infrared spectroscopy; a-AMPs, Alpha helical antimicrobial peptides; $\Delta \mathrm{G}_{\mathrm{Mix}}$, Gibbs free energy of mixing. 


\begin{abstract}
VP1, a putative a-helical antimicrobial peptide (a-AMP) inhibited growth of Bacillus subtilis and Escherichia coli at $500 \mu \mathrm{M}$. The peptide induced stable surface pressure changes in monolayers formed from B. subtilis native lipid extract (circa $4.5 \mathrm{mN} \mathrm{m}^{-1}$ ) but transient pressure changes in corresponding E. coli monolayers ( $\operatorname{circa} 1.0 \mathrm{mN} \mathrm{m}^{-1}$ ), which led to monolayer disintegration. Synthetic lipid monolayers mimetic of the extracts were used to generate compression isotherms. Thermodynamic analysis of $B$. subtilis isotherms indicated membrane stabilisation by VP1 $\left(\Delta \mathrm{G}_{\text {Mix }}<0\right)$, via a mechanism dependent upon the phosphatidylglycerol to cardiolipin ratio. Corresponding analysis of $E$. coli isotherms indicated membrane destabilisation by the peptide $\left(\Delta \mathrm{G}_{\text {Mix }}>0\right)$. Destabilisation correlated with PE levels present and appeared to involve a mechanism resembling those used by tilted peptides. These data emphasise that structure / function analysis of a-AMPs must consider not only their structural characteristics but also the lipid make-up of the target microbial membrane.
\end{abstract}




\section{Introduction}

Over the last twenty-five years, there has been widespread research into the potential of antimicrobial peptides to act as novel antibiotics (Giuliani et al., 2007; Mookherjee \& Hancock, 2007; Nizet, 2007; Zaiou, 2007). In this capacity, amongst the most extensively studied of these agents are peptides that adopt an a-helical structure (a-AMPs) to exert their antimicrobial activity (Castro et al., 2006; Zelezetsky \& Tossi, 2006). These peptides are produced by a diverse variety of organisms ranging from amphibians (Apponyi et al., 2004; Boland \& Separovic, 2006) to insects (Bulet \& Stocklin, 2005; Tamang \& Saier, 2006) and are able to kill an extraordinarily wide spectrum of cells and microbes, ranging from bacteria (Durr et al., 2006) to tumour cells (Dennison et al., 2006).

All known a-AMPs appear to be lipid interactive, either passing through the membrane to attack intracellular targets or, as in most cases, using direct invasion of the microbial membrane itself as their primary killing mechanism (Bechinger \& Lohner, 2006; Sato \& Feix, 2006). The relatively non-specific nature of these mechanisms of antimicrobial action is reflected in a general lack of microbial resistance to a-AMPs and where such resistance has been reported, levels are much lower than those shown by microbes to conventional antibiotics. Indeed, a-AMPs show many potential advantages over these latter antibiotics and are viewed as attractive alternatives in the fight against the current global problem of microbial pathogens with multi-drug resistance (Jenssen et al., 2006; Marr et al., 2006).

Despite intensive study, detailed descriptions for the microbial killing mechanisms used by aAMPs are still lacking. Most a-AMPs are cationic and are presumed to target bacterial cells via electrostatic interactions with negatively charged moieties in the bacterial envelope. These include anionic lipids and lipopolysaccharide (LPS) phosphate groups in the case of the Gram-negative outer membrane and techoic acids in the case of the Gram-positive membrane (Nizet, 2007). Once a-AMPs have gained access to the cytoplasmic membrane of bacteria, they are able to invade the lipid bilayer and a number of general models have been presented to describe such invasion. These models variously propose that a-AMPs form "barrel stave" membrane pores or "carpet" the membrane, which can then lead to toroidal membrane pore formation or solubilisation of the membrane in a detergent like manner. These a-AMP membrane interactions then lead to lysis or permeabilisation of target 
microbial cells (Bechinger \& Lohner, 2006; Sato \& Feix, 2006). The Shai-Huang-Matsazuki (SHM) model was recently presented and incorporates aspects from several of these former models. Essentially, the SHM model proposes that "carpeting" of the microbial membrane with $\alpha$-AMPs leads to the displacement of membrane lipid, alterations to membrane structure and either microbial membrane destruction or peptide internalization (Zasloff, 2002). Most recently, theoretical analyses (Dennison et al., 2005b) supported by experimental evidence (Marcotte et al., 2003), have suggested that some $\alpha$-AMPs may invade microbial membranes via the use of oblique orientated a-helices, or tilted peptides. The vast majority of membrane interactive $\alpha$-helices possess relatively constant levels of hydrophobicity along the $\alpha$-helical long axis, leading these $\alpha$-helices to adopt stable membrane orientations that are either approximately parallel or perpendicular to the membrane surface, as generally assumed for lipid interactive $\alpha$-AMPs. However, in contrast, oblique orientated $\alpha$-helices possess a strong gradient in the level of hydrophobicity along their helical long axis. These hydrophobicity gradients allow the protein $\alpha$-helices to penetrate the membrane at an angle between $30^{\circ}$ and $60^{\circ}$, thereby promoting the destabilisation of lipid organisation and leading to a range of effects such as the generation of non-bilayer structures and membrane fusion (Brasseur, 2000; Harris et al., 2000; Rahman et al., 1997; Thomas \& Brasseur, 2006). The $\alpha$-helix formed by VP1, a cationic peptide derived from m-calpain (Brandenburg et al, 2002), shows many of the structural characteristics possessed by membrane interactive oblique orientated $\alpha$-helices (Dennison et al., 2005a) as shown by comparisons to aurein 1.2 and citropin 1.1 (Fig. 1), which are known cationic tilted peptides from Australian tree frogs (Boland \& Separovic, 2006) with a-AMP properties. It has previously been shown that these three peptides are active at the membrane interface and possess a balance between the levels of amphiphilicity and hydrophobicity that are associated with tilted a-AMPs (Dennison et al., 2005b), thus making VP1 a candidate antibacterial.

In general, the construction of models to describe microbial membrane invasion by a-AMPs has been based on data obtained from studies involving model membranes. These studies have established that interaction of a-AMPs with membrane lipid involves a number of key structural properties possessed by these peptides, such as residue composition, charge, hydrophobicity and amphiphilicity. It is also well established that the broad-range antimicrobial activity of a-AMPs requires that they are able to invade membranes with widely varying lipid compositions. However, few studies appear to have considered how this 
variability influences the mechanisms of membrane invasion used by these peptides. In response, we have used the approach of Henzler-Wildman et al., (2004) who utilised model membranes formed from bacterial lipid extracts or synthetic lipid mixes to investigate the bacterial membrane interactions of the human a-AMP LL-37 (Henzler-Wildman et al., 2004). We employ monolayers formed from whole lipid extracts of Bacillus subtilis and Escherichia coli to study the bacterial membrane interactions of VP1. These native bacterial lipid monolayers are then mimicked using synthetic lipid mixes with know composition to generate compression isotherms and facilitate thermodynamic analysis of these VP1membrane interactions. Based on the results of these studies in conjunction with those obtained from FTIR lipid phase transition analysis and bacterial toxicity assay of the peptide, we propose models for the antibacterial action of the peptide.

\section{Experimental Procedures}

\subsection{Materials}

The synthetic peptide, VP1 (GTAMRILGGVI), was supplied by PEPSYN (UK), synthesised by solid state synthesis and purified by HPLC to purity greater than $99 \%$, confirmed by MALDI mass spectrometry. Nutrient broth, Luria Bertani broth (LBB) and Tryptic soy broth were purchased from LabM (UK). Buffers and solutions for monolayer experiments were prepared from Milli-Q water. Dioleoylphosphatidylglycerol (DOPG) and dioleoylphosphatidylethanolamine (DOPE) were purchased from AlexisCorporation (UK).

Cardiolipin (CL) from E. coli was purchased from Avanti. Tris (Tris $\{$ hydroxymethyl $\}$ aminomethane), HEPES （N-[2-Hydroxyethylpiperazine-N'-[2ethanesulphonic acid]) and all other reagents were purchased from Sigma (UK).

\subsection{Methods}

\subsubsection{Activity of VP1 against planktonic bacteria}

Cultures of B. subtilis, strain NCIMB 8054, and E. coli, strain W3110, which had been freeze-dried in $20 \%(\mathrm{v} / \mathrm{v})$ glycerol and stored at $-80{ }^{\circ} \mathrm{C}$, were each used to inoculate two 10 $\mathrm{ml}$ aliquots of nutrient broth. After overnight incubation in an orbital shaker (100 rpm, 37 $\left.{ }^{\circ} \mathrm{C}\right), 100 \mu \mathrm{l}$ of each culture was used to inoculate two $100 \mathrm{ml}$ aliquots of nutrient broth in 250 $\mathrm{ml}$ flasks, which were then incubated with shaking (100 rpm, $\left.37^{\circ} \mathrm{C}\right)$ until the exponential phase was reached $(\mathrm{OD}=0.6 ; \lambda=600 \mathrm{~nm})$. A $1 \mathrm{ml}$ aliquot of each bacterial sample was centrifuged $\left(15000 \mathrm{~g}, 3 \mathrm{~min}, 25^{\circ} \mathrm{C}\right)$ using a bench top centrifuge and the resulting pellet washed three times in $1 \mathrm{ml}$ aliquots of Tris $(10 \mathrm{mM}, \mathrm{pH} 7.5)$. For each sample, cells were 
then re-suspended in $1 \mathrm{ml}$ of this buffer containing VP1 at a final concentration of $3 \mathrm{mM}$, which had previously been determined as its minimum lethal concentration (MLC) for both $B$. subtilis and E. coli in the range 0 to $5 \mathrm{mM}$. These culture / peptide mixtures were incubated at $37{ }^{\circ} \mathrm{C}$ and samples taken at the beginning of the experiment (time zero), and at 15 minute intervals for 1 hour and then hourly intervals for 7 hours. As a control, cultures of both bacterial strains were similarly treated but in the absence of peptide. At each sampling, $10 \mu \mathrm{l}$ of culture was removed and a ten-fold serial dilution $\left(10^{-1}\right.$ to $\left.10^{-7}\right)$ prepared in Tris (25 $\mathrm{mM}, \mathrm{pH} 7.5)$. Aliquots $(10 \mu \mathrm{l})$ of each dilution were surface-spread onto nutrient agar plates, which were then incubated at $37{ }^{\circ} \mathrm{C}$ for 12 hours. Colony counts were undertaken and expressed as colony forming units (CFUs) $\mathrm{ml}^{-1}$. The percentage reduction in colonies for each time interval was calculated and recorded as a function of time.

\subsubsection{Activity of VP1 against bacterial biofilms}

Biofilms of B. subtilis, strain NCIMB 8054, and E. coli, strain W3110 were prepared in two separate BD Falcon tissue culture slides. Strains were grown for 24 hours at $37{ }^{\circ} \mathrm{C}$ in $10 \mathrm{ml}$ Luria Bertani broth (LBB) for E. coli and in Tryptic soy broth for B. subtilis. Aliquots $(0.75$ $\mathrm{ml}$ ) of each broth were dispensed separately into the 8 well BD Falcon tissue culture slides and $10 \mu \mathrm{L}$ of each overnight culture was inoculated into each chamber of the chamber slide. For biofilm formation the incubation time was $24 \mathrm{~h}$ at $37^{\circ} \mathrm{C}$. The medium from the wells was then removed using a pipette and the biofilm was washed in sterile distilled water to ensure all planktonic cells were removed. Aliquots of $0.5 \mathrm{~mL}$ of peptide solution $(8 \mathrm{mM})$ of decreasing concentrations (ranging from $4 \mathrm{mM}$ to $0.0625 \mathrm{mM}$ ) were prepared by a series of doubling dilution with $1 / 4$ strength Ringers. The biofilms in each well of the culture slides were then treated with a $0.5 \mathrm{ml}$ of VP1 peptide stock solutions. The slides were then incubated for $24 \mathrm{~h}$ at $37^{\circ} \mathrm{C}$. After incubation, the wells were emptied and the plastic chamber removed. The slides were then stained with Vetashield mounting medium containing propidium iodide solution $\left(1.5 \mathrm{\mu g} \mathrm{ml}^{-1}\right)$, for 20 minutes at room temperature. Examination of the stained biofilm slides was performed using fluorescence microscopy Images were recorded at $480 \mathrm{~nm}$ excitation and at $530 \mathrm{~nm}$ emission.

\subsubsection{Total lipid extracts from cells of B. subtilis and E. coli}

Total lipid extracts of $B$. subtilis and E. coli were obtained using a modified form of the procedure first described by Bligh and Dyer (Bligh \& Dyer, 1959). Essentially, cultures of these organisms were separately grown in nutrient broth as described above. When in the 
exponential phase $(\mathrm{OD}=0.6 ; \lambda=600 \mathrm{~nm}), 1 \mathrm{ml}$ of each culture was extracted, washed twice in Tris buffer ( $25 \mathrm{mM}, \mathrm{pH} 7.5)$ and centrifuged (15000 g, $5 \mathrm{~min})$ to form a pellet. Each pellet was then resuspended in $1 \mathrm{ml}$ Tris buffer $(25 \mathrm{mM}, \mathrm{pH} 7.5)$ and to a $0.4 \mathrm{ml}$ aliquot of this cell suspension, $1.5 \mathrm{ml}$ of a 1:2 (v/v) chloroform - methanol mixture was added. Each of these cell / solvent samples was then vortexed vigorously for 5 minutes, a further $0.5 \mathrm{ml}$ chloroform added and the whole again vortexed for 5 minutes. To each sample, $0.5 \mathrm{ml}$ water was added, the whole vortexed for 5 minutes and then centrifuged at low speed $(660 \mathrm{~g}, 5$ $\min$ ) to produce two phases. The lower organic layer was transferred to a fresh centrifuge tube, concentrated using a Jouran speed vac (Jouran, UK) and the dried lipid extract stored at $-20{ }^{\circ} \mathrm{C}$ under $\mathrm{N}_{2}$.

\subsubsection{FTIR spectroscopic analyses of VP1 - lipid interactions}

\subsubsection{Preparation of lipid vesicles}

Lipid vesicles were prepared according to Keller et al., (Keller et al., 1992). Essentially, total lipid extracts of B. subtilis and E. coli, respectively, were resuspended in chloroform, dried with nitrogen gas and hydrated with HEPES (10 mM, pH 7.5) to give final total lipid concentrations of $150 \mathrm{mM}$. The resulting cloudy suspensions were sonicated at $4{ }^{\circ} \mathrm{C}$ with a Soniprep 150 (ISTCP, USA) sonicator (amplitude 10 microns) until clear (30 cycles of 30 seconds) and then centrifuged (15 min, $\left.3000 \mathrm{~g}, 4{ }^{\circ} \mathrm{C}\right)$.

\subsubsection{FTIR analysis of VP1 effects on lipid phase transition properties}

The final VP1 concentration of $3 \mathrm{mM}$ was obtained by solubilising the peptide in vesicle suspensions formed from the total lipid extracts of B. subtilis and E. coli. Corresponding suspensions of vesicles were prepared with no peptide present served as controls. All samples were then subjected to automatic temperature scans with a heating rate of $3{ }^{\circ} \mathrm{C}(5$ $\mathrm{min})^{-1}$ and within the temperature range $0{ }^{\circ} \mathrm{C}$ to $60{ }^{\circ} \mathrm{C}$. For every $3{ }^{\circ} \mathrm{C}$ interval, 50 interferograms were accumulated, apodized, Fourier transformed and converted to absorbance spectra (Brandenburg et al., 1997). These spectra monitored changes in the $\beta$ $\leftarrow \alpha$ acyl chain melting behaviour of phospholipids with these changes determined as shifts in the peak position of the symmetric stretching vibration of the methylene groups, $v_{\mathrm{s}}\left(\mathrm{CH}_{2}\right)$, which is known to be a sensitive marker of lipid order. The peak position of $v_{\mathrm{s}}\left(\mathrm{CH}_{2}\right)$ lies at $2850 \mathrm{~cm}^{-1}$ in the gel phase and shifts at a lipid specific temperature $T_{c}$ to $2852.0 \mathrm{~cm}^{-1}$ $2852.5 \mathrm{~cm}^{-1}$ in the liquid crystalline state. 


\subsubsection{Lipid monolayer studies on VP1}

\subsubsection{Langmuir-Blodgett system}

Monolayer investigations were performed using Langmuir-Blodgett equipment supplied by NIMA (UK), which was mounted on a vibration-isolated table. Studies were conducted using a Teflon trough, which possessed surface area dimensions of $5 \mathrm{~cm} \times 16 \mathrm{~cm}$ and held a volume of $80 \mathrm{ml}$, and was fitted with two mechanically coupled Delrin barriers (Hardy et al., 2006). All experiments were conducted at an operating temperature of $21.0 \pm 1{ }^{\circ} \mathrm{C}$ and used a subphase of Tris (10 mM, pH 7.5), which had been prepared with purified MilliQ water (specific resistance $18 \mathrm{M} \Omega \mathrm{cm}$ ). Unless indicated otherwise, VP1 was introduced into the subphase via an injection port to give desired final concentrations. The subphase was continuously stirred by a magnetic bar $(5 \mathrm{rpm})$ and surface tension was monitored by the Wilhelmy method using a paper plate (Whatman's Ch1) in conjunction with a microbalance, as described by Demel (Demel, 1974). Contaminants were removed from the subphase surface by aspiration and a stable surface pressure taken to be that with fluctuations of less than $0.01 \mathrm{mN} \mathrm{m}^{-1}$. Changes in monolayer surface pressure/area were recorded as graphic output on a PC using NIMA software, which interfaced with the Langmuir-Blodgett microbalance.

\subsubsection{VP1 interactions with lipid monolayers}

The ability of VP1 to penetrate lipid monolayers at constant area was studied. Monolayers were formed by spreading chloroform solutions of total lipid extract from B. subtilis and $E$. coli respectively onto a Tris subphase. Additionally, monolayers were formed by spreading chloroform solutions of synthetic lipid mixes, which were designed to mimic membranes of B. subtilis and E. coli respectively onto the Tris subphase. These latter monolayers were formed from DOPG, DOPE and CL in the molar ratios described in Table 1. After spreading, the solvent was allowed to evaporate off the subphase of the surface over 30 minutes and then the lipid monolayer was compressed at a velocity of $5 \mathrm{~cm}^{2} \mathrm{~min}^{-1}$ to give a surface pressure of $30 \mathrm{mN} \mathrm{m}^{-1}$. The barriers were maintained in this position and VP1 was introduced into the Tris subphase to achieve a peptide concentration of $20 \mu \mathrm{M}$, which was determined as optimal for these experimental conditions (Dennison et al., 2005a). Interactions of the peptide with lipid monolayers were monitored as changes in monolayer surface pressure versus time. 
The ability of VP1 to interact with lipid monolayers was also investigated using compression isotherms. Monolayers were formed by spreading chloroform solutions of either DOPG, DOPE, CL or synthetic lipid mixes (Table 1) on to a $10 \mathrm{mM}$ Tris buffer subphase. Additionally monolayers formed on a Tris buffer subphase using the lipid mixes as described in Table 1, but with PE molar ratios that varied between 3.5 and 15, and CL / PG mixtures at molar ratios that varied between 0.5 and 3.0. After spreading, the solvent was allowed to evaporate off the subphase surface over 30 minutes and then the lipid monolayer compressed using a barrier speed of $5 \mathrm{~cm} \mathrm{~min}^{-1}$ until monolayer collapse pressure was achieved. These experiments were repeated except that VP1 was introduced into the subphase to give a final peptide concentration of $20 \mu \mathrm{M}$. For all compression isotherms, changes in lipid monolayer surface pressure with changes in monolayer area were recorded.

\subsubsection{Thermodynamic analysis of VP1 interactions with lipid monolayer isotherms}

The phase state of monolayers was studied using the compressibility modulus $\left(\mathrm{C}_{\mathrm{s}}^{-1}\right)$. This parameter provides a measure of the compressional elasticity of a lipid monolayer, thereby providing information about lipid packing within the monolayer (Alminana et al., 2004), and is given by:

$$
C_{s}^{-1}=-A\left(\frac{\delta \pi}{\delta A}\right) \ldots \ldots \ldots
$$

where $(\Pi)$ represents monolayer surface pressure and $(A)$ is the area per molecule in the monolayer.

The thermodynamic stability of monolayers was investigated using the Gibbs free energy of mixing $\left(\Delta \mathrm{G}_{M i x}\right)$. This parameter provides a measure of the relative stability of a monolayer by considering the energetics of miscibility of its pure lipid components and is given by:

$$
\Delta G_{M A x}=\int_{0}^{\pi}\left[A_{12 \ldots n}-\left(X_{1} A_{1}+X_{2} A_{2} \ldots+X_{n} A_{n}\right) d \pi\right]
$$

where $A_{1,2, \ldots n}$ is the molecular area occupied by the mixed monolayer, $\mathrm{A}_{1}, \mathrm{~A}_{2} \ldots \mathrm{A}_{n}$ are the area per molecule in the pure monolayers of component $1,2, \ldots \mathrm{n}, X_{1}, X_{2} \ldots \mathrm{X}_{n}$ are the molar fractions of the components and $\Pi$ is the surface pressure. Numerical data were calculated from the compression isotherms according to the mathematical method of Simpson (Todd, 1963). 
The interactions between component lipid molecules of monolayers were examined using the interaction parameter (a). This parameter relates the interaction of each molar fraction of lipid in a monolayer to the energy gain through mixing of the monolayer and is given by:

$$
\alpha=\frac{\Delta G_{M i x}}{R T\left(X_{1} X_{n}^{n}+X_{1}^{n} X_{n}\right)} \ldots \ldots
$$

where $X$ are the molar fractions of the monolayer lipid components, $R=8.314 \mathrm{~J} \mathrm{~mol}^{-1} \mathrm{~K}^{-1}$ and $T=294^{\circ} \mathrm{K}$.

The stability and binding interactions of monolayers were further investigated using the mixing enthalpy $(\Delta \mathrm{H})$, which is given by:

$$
\Delta \mathrm{H}=\frac{R T \alpha}{\mathrm{Z}} \ldots \ldots \ldots . \mathbf{E q} \cdot \mathbf{4}
$$

where $R$ and $\mathrm{T}$ are as defined in equation 5 , and $\mathrm{Z}$ is the packing fraction parameter, which is calculated using the Quikenden and Tam model (Quickenden \& Tan, 1974).

\section{Results}

\subsection{VP1 toxicity to bacterial strains}

When directed against planktonic bacteria, it was found that $3 \mathrm{mM} \mathrm{VP1} \mathrm{took} 4 \mathrm{hr}$ to induce $100 \%$ cell death in the case of $B$. subtilis but $1 \mathrm{hr}$ for $E$. coli under corresponding conditions (Fig. 2A). This represents a significant difference in the rates at which VP1 induces cell death in these latter organisms as confirmed by use of the Friedman's test $(\mathrm{p}=0.003)$ and indicates that the peptide has an ability to kill E. coli more rapidly than B. subtlis. When directed against bacterial biofilms, VP1 exhibited an MIC $=500 \mu \mathrm{M}$ and an MLC of $4 \mathrm{mM}$ against both B. subtilis and E. coli (Fig. 2B).

\subsection{FTIR spectroscopic analyses of VP1 - lipid interactions}

FTIR lipid phase transition analysis showed that in the absence of VP1, vesicles formed from total lipid extracts of B. subtilis and E. coli showed different phase transition properties (Fig. 3A and Fig. 3B). In the case of B. subtilis the fluidity of the membranes underwent a general rise in wavenumber with temperature (Fig. 3A) which is indicative of a monotonous increase of the acyl chain length. In contrast, the E. coli membrane system (Fig. 3B) underwent a 
clear transition from the gel phase to liquid crystalline phase over the temperature range 25 ${ }^{\circ} \mathrm{C}$ to $40{ }^{\circ} \mathrm{C}$ with a concomitant increase in membrane fluidity as indicated by the rise in wavenumber from circa $2851.5 \mathrm{~cm}^{-1}$ to $2853.5 \mathrm{~cm}^{-1}$. In the presence of VP1, there is no significant change in the melting temperature range of both systems but significant changes in membrane fluidity were exhibited. For E. coli the fluidity of membranes underwent a significant decrease as indicated by a general fall in wavenumber of between 0.5 to $1.0 \mathrm{~cm}^{-1}$ (Fig. 3B), which is in contrast to B. subtilis where there was an increase in fluidity of comparable magnitude.

\subsection{VP1-lipid monolayer interactions at constant area}

The interactions of VP1 with monolayers that mimicked the membranes of B. subtilis and $E$. coli were investigated at constant area. For each organism, monolayers formed from total lipid extracts or synthetic lipid mixes (Table 1), were found to form stable monolayers at a surface pressure of $30 \mathrm{mN} \mathrm{m}^{-1}$ (Fig. 4A and Fig. 4B), which was taken to represent that of naturally occurring membranes (Blume, 1979; Marshall \& Arenas, 2003; Ronzon et al., 2002; Seelig, 1987). VP1 induced stable increases in the surface pressure of both monolayers tested in the case of $B$. subtilis membrane mimics and after $4000 \mathrm{sec}$ these pressure increases reached maximal values of $4.5 \mathrm{mN} \mathrm{m}^{-1}$ in the case of synthetic membrane mixes and $3.0 \mathrm{mN}$ $\mathrm{m}^{-1}$ in the case of total lipid extracts (Fig. 4A). In contrast, for E. coli membrane mimics, the peptide induced maximal surface pressure increases of $2.5 \mathrm{mN} \mathrm{m}^{-1}$ in monolayers formed from synthetic lipid mixes and $1 \mathrm{mN} \mathrm{m}^{-1}$ in those formed from total lipid extracts. For these latter monolayers, after a period of apparent stability, a decrease in surface pressure was then observed, which after $1500 \mathrm{sec}$ led to surface pressures values lower than that of original monolayer, indicative of monolayer disintegration (Fig. 4B).

\subsection{VP1-lipid compression isotherms and their thermodynamic analysis}

Compression isotherms were obtained for monolayers formed from synthetic lipid mimics of B. subtilis and E. coli membranes respectively (Fig. 5A), and from each individual component lipid of these membrane-mimics (Fig. 5C). Corresponding compression isotherms were obtained for these monolayers in the presence of VP1 (Fig. 5B and Fig. 5D). For these B. subtilis and E. coli model membranes, data from Fig. 5 and equation 1 were used to calculate the values of $\mathrm{C}_{\mathrm{s}}^{-1}$ (Table 2). Table 2 shows that these isotherms have low values of $\mathrm{C}_{\mathrm{s}}^{-1}$, indicating that all monolayers were in a liquid expanded phase (Davies \& Rideal, 1963) and thus were fluid with high compressibility. Table 2 also shows that in the presence of 
VP1, a general decrease in $\mathrm{C}_{\mathrm{s}}^{-1}$ was observed with rising surface pressure, indicating monolayer expansion due to peptide interactions.

The isotherms from Fig. 5 were also used to calculate the Gibbs free energy of mixing $\left(\Delta \mathrm{G}_{M i x}\right)$. Table 3 shows that for both organisms, $\Delta \mathrm{G}_{M i x} \ll R T=2444.316 \mathrm{~J} \mathrm{~mol}^{-1}$, indicating that deviations from ideal mixing behaviour in these model membranes are small (Sospedra et al., 2001). Table 3 also shows for both model membranes, $\Delta \mathrm{G}_{M i x}$ varies with surface pressure and according to the absence or presence of VP1. In the absence of VP1, values of $\Delta \mathrm{G}_{\text {Mix }}>0$ were observed for $B$. subtilis model membranes indicating energetically unstable interactions between the individual lipid components of these membranes. However, in the presence of VP1, $\Delta \mathrm{G}_{\text {Mix }}<0$, indicating that there are attractive interactions between the individual monolayer components, in turn, implying that the monolayer is stable. These values of $\Delta \mathrm{G}_{M i x}$ for the lipid:peptide mix become increasingly more negative with increasing surface pressure, showing that at higher surface pressures, these monolayer mimics of $B$. subtilis are more stable than the monolayers formed by their pure components. In contrast, in the absence of VP1, values of $\Delta \mathrm{G}_{\text {Mix }}<0$ were observed for $E$. coli model membranes, indicating a stable monolayer. However, in the presence of $\mathrm{VP} 1, \Delta \mathrm{G}_{M i x}>0$, indicated that although the monolayer components are miscible, interactions are destabilised by the peptide, thereby decreasing membrane stability. Values of $\Delta \mathrm{G}_{M i x}$ increased with rising surface pressure, implying that these E. coli model membranes became increasingly less stable with compression

Isotherms of CL:PG monolayers with varying lipid ratios were analysed. At a ratio of 1.6:1, which corresponds to that found in B. subtilis membranes (Table 1), $\Delta \mathrm{G}_{M i x}$ changed from +200 to - 100 on addition of VP1 (Fig. 6), indicating a stabilising effect. In contrast, at a CL:PG ratio of 2:1, which corresponds to that found in E. coli membranes (Table 1), $\Delta \mathrm{G}_{\text {Mix }}$ was +400 and was not significantly affected by the presence of VP1 (Fig. 6). Similar analysis of compression isotherms was conducted where CL:PG ratios were held at those corresponding to B. subtilis or E. coli membranes respectively (Table 1) and PE was progressively introduced into these systems (Fig. 7 and Fig. 8). In the case of B. subtilis membrane mimics, increasing levels of PE had no significant effect on the stability of these membranes around the CL:PG ratio found in this organism with the presence of PE causing $\Delta \mathrm{G}_{\text {Mix }}$ to vary by only \pm 50 in the presence and absence of VP1 over the range tested (Fig. 7). 
In contrast, with CL:PG ratios corresponding to $E$. coli membrane mimics, increasing levels of PE caused $\Delta \mathrm{G}_{M i x}$ to move from +450 to -400 in the absence of VP1 but from +450 to +100 in the presence of VP1 (Fig. 8), indicating a clear stabilising effect on membrane stability by the presence of PE but a destabilising effect by the peptide.

Further thermodynamic analysis of isotherms in Fig. 5 was undertaken and the interaction parameter (a) and mixing enthalpy $(\Delta \mathrm{H})$ were calculated for these monolayers using equations 3 and 4 . Table 4 shows that in the absence of VP1, both a and $\Delta H>0$ for $B$. subtilis model membranes and $<0$ for those of E. coli. However, in the presence of VP1, a and $\Delta \mathrm{H}<0$ for $B$. subtilis model membranes and $>0$ for those of $E$. coli. These data indicate that in the case of $E$. coli, membranes are thermodynamically less stable in the presence of VP1 than those of $B$. subtilis.

\section{Discussion}

VP1 was found to possess weak antibacterial activity, exhibiting an MLC of $3 \mathrm{mM}$ against planktonic E. coli and B. subtilis and an MIC of $500 \mu \mathrm{M}$ against biofilms formed from these organisms (Fig. 2), the metric generally used to characterise such anti-biofilm activity (Curtin \& Cormican, 2003). However, for comparative purposes, the MLC of VP1 against these latter biofilms was also determined and found to be $4 \mathrm{mM}$, which is consistent with the view that biofilms of organisms are more resistant to biocides than their planktonic counterparts, primarily due to the development of resistant phenotypes within the biofilm (del Pozo \& Patel, 2007; Rodriguez-Martinez \& Pascual, 2006). These higher levels of resistance may be explained in part by the presence of exopolysaccharides (EPS) in the extracellular matrix of bacterial biofilms. It has been shown that EPS possess structural properties mimetic of bacterial membranes, enabling them to bind $\alpha$-AMPs with mean hydrophobicity above a threshold of 0.4 as measured using the Liu-Deber hydrophobicity scale, effectively increasing the level of peptide required for biofilm killing (Chan et al., 2004; Kuo et al., 2007). Analysis of VP1 according to Chan et al., (2004) shows VP1 to be sufficiently hydrophobic to engage in such EPS interactions since it has a mean hydrophobicity of 0.56 .

Toxicity assay showed comparable levels of VP1 were required to inactivate $B$. subtilis and E. coli in both their biofilm and planktonic forms (Fig. 2). In the latter case though E. coli was killed four times faster than B. subtilis (Fig. 2A), suggesting that differing methods of 
antimicrobial action may be involved. To investigate this suggestion further, the interactions of VP1 with membranes of B. subtilis and E. coli were undertaken using lipid monolayers at an initial surface pressure $\left(30 \mathrm{mN} \mathrm{m}^{-1}\right)$ characteristic of naturally occurring bacterial membranes. In the case of monolayers formed from B. subtilis membrane lipid extract, VP1 showed maximal levels of interaction $\left(3 \mathrm{mN} \mathrm{m}^{-1}\right)$ that were consistent with penetration of the monolayer headgroup region by the peptide (Fig. 4A). It is well established that Gram positive bacteria possess high levels of anionic lipid (Devine \& Hancock, 2002; Zelezetsky \& Tossi, 2006), which would clearly facilitate strong surface interactions between B. subtilis membranes and positively charged VP1. Such stable binding would fit with membrane association characteristic of carpet based mechanisms of action.

In contrast, VP1 showed initial interactions with monolayers formed from E. coli lipid extract (Fig. 4B) that led to lower levels of maximal interaction $\left(1 \mathrm{mN} \mathrm{m}^{-1}\right)$, which could correlate with the relatively reduced levels of anionic lipid possessed by membranes of Gram-negative organisms when compared to those of Gram-positive bacteria (Devine \& Hancock, 2002; Zelezetsky \& Tossi, 2006). However, after a short plateau region, in the case of E. coli, the kinetics of these initial interactions were superseded by those indicating monolayer disintegration, which clearly, must involve destabilisation of the lipid packing in these monolayers by VP1 with lipid reordering resulting. These results strongly suggest that in the case of E. coli the peptide uses a lytic mechanism, which resembles those that solubilise the membrane in a detergent like manner (Bechinger \& Lohner, 2006; Sato \& Feix, 2006) and involves disturbance of lipid acyl chains within the E. coli membrane core as previous reported in the case of membrane disruption by oblique orientated $\alpha$-helices (Brasseur, 2000; Thomas \& Brasseur, 2006).

To try and gain a further understanding of these differing effects, thermodynamic analysis of VP1 interactions with $B$. subtilis and $E$. coli membranes along with compression isotherm analysis was undertaken using monolayers formed from synthetic lipid mixes rather than bacterial total lipid extracts. Control experiments at constant area established that the synthetic monolayers provided a good model with VP1 showing comparable levels of interaction and similar kinetics to those observed from monolayers formed from lipid extracts (Fig. 4). Whilst it is recognised that these systems lack a range of non-lipid components 
(Brogden, 2005), such studies are well documented as providing information regarding the important role of the lipid components with respect to the mode of action.

Isotherm analyses of monolayers representing $B$. subtilis membranes showed that $\Delta \mathrm{G}_{\text {Mix }}$ was negative in the presence of VP1 but positive in its absence (Table 3), which in combination indicate that the peptide had a thermodynamically stabilising effect on these systems. Further analysis by varying the lipid composition, suggested that VP1 driven stabilization of $B$. subtilis membranes was dependent upon the to CL:PG ratio given that at a CL:PG ratio representing that of the organism (1.6:1, Table 1) and below, VP1 is seen to stabilise the system (Fig. 6). Above this CL:PG ratio, the system appears more stable and is less affected by VP1.

Isotherm analyses of $E$. coli membranes showed that $\Delta \mathrm{G}_{M i x}$ was positive in the presence of VP1 but negative in its absence (Table 3), which together indicate that the peptide had a thermodynamically destabilising effect on these membranes. The importance of the CL:PG ratio, as described above, appears to be confirmed when the lipid composition was varied to achieve higher CL:PG ratios, which include that representative of E. coli membranes (2:1, Table 1). At these ratios it can be seen that there is little effect on membrane stability upon VP1 addition (Fig. 6). However, increasing the level of PE from zero to that found in the organism led to VP1 destabilising the lipid system, generating a change in $\Delta \mathrm{G}_{M i x}$ that went from +450 to -400 in the absence of VP1 but from +450 to +100 in the presence of VP1 (Fig. 8). These results imply that at this CL:PG ratio, the presence of PE was required for the VP1 destabilising effect observed for E. coli membranes. In contrast, increasing the level of PE from zero to a level comparable to that found in B. subtilis at the CL:PG ratio of this organism showed little effect on the action of VP1 (Fig. 7), confirming the importance of the $\mathrm{CL}: \mathrm{PG}$ ratio in this latter case.

These data clearly reinforce the suggestion that VP1 promotes its toxicity to B. subtilis through a mechanism of membrane invasion, which differs to that used in the case of E. coli and that these differences are due to lipid composition. The differences in the membranes dynamics were supported by FTIR, which showed a clear phase change in case of the more stable E. coli system but not in the case of the less stable B. subtilis system. Lipid phase transition analysis was used to investigate the possibility that differences in the antimicrobial efficacy of VP1 may be related to the differing characteristics of these target membranes. A 
significant decrease in the membrane fluidity for $E$. coli extracts was observed in the presence of VP1 (Fig. 3B), which suggests that VP1 affects the hydrophobic membrane core in contrast to the effect seen for B. subtilis (Fig. 3A).

The lipid phase transition data (Fig. 3) imply that the interaction of VP1 with B. subtilis membranes involves lipid headgroup binding in a stable manner, which would further support a mode of action based on the carpet type mechanism. In the case of E. coli, the data support the proposal that VP1 invasion of the organism's membranes may involve penetration of the membrane lipid core and membrane destabilisation followed by membrane solubilisation and lysis. It is well established that the ability of tilted peptides to destabilise membranes is enhanced by the preference of PE to adopt non-bilayer structures (Bechinger \& Lohner, 2006; Thomas \& Brasseur, 2006). Taken with these isotherm data and theoretical analyses of the VP1 a-helix (Dennison et al., 2005b) these observations would support the suggestion that the peptide promotes toxicity to E. coli via the use of membrane interactive oblique orientated a-helical structure. Similar mechanisms of antibacterial action have been proposed for aurein 1.2 and citropin 1.1 (Dennison et al., 2005b; Marcotte et al., 2003), which are of comparable length to VP1 and have similar characteristics (Fig 1A). These amphibian peptides have been shown to insert into lipid mimics of the bacterial membrane, resulting in membrane destabilisation and lysis via carpet-type mechanisms but are able to form oblique orientated structure (Ambroggio et al., 2004; Ambroggio et al., 2005; Balla et al., 2004; Boland \& Separovic, 2006).

In conclusion, VP1 functions as a weak a-AMP, killing E. coli and B. subtilis, at comparable levels. The peptide thus shows a comparable ability to kill both Gram-positive and Gramnegative bacteria but appears to act via different mechanisms of membrane invasion in the two cases investigated. Differences between these mechanisms appear to depend upon the relative composition, stability and lipid packing characteristics of the target bacterial membrane. Taken overall, the results of this study emphasise the fact that a given a-AMP can utilise more than one mechanism of antimicrobial action, which is reinforced by recent studies (Ramamoorthy et al., 2006). It is thus clearly imperative that structure / function analyses of a-AMPs must take into account not only their own structural characteristics but also the make-up of the membrane target. 


\section{Acknowledgements}

The authors thank Jörg Howe and Klaus Brandenburg, Division of Biophysics, Forschunginstitut Borstel, Germany for their assistance with FTIR analysis.

\section{References}

Alminana, N., Alsina, M. A., Ortiz, A., Reig, F. 2004. Comparative physicochemical study of SIKVAV peptide and its retro and retro-enantio analogues. Colloids Surf. A Physicochem. Eng. Asp. 249, 19-24.

Ambroggio, E. E., Separovic, F., Bowie, J., Fidelio, G. D. 2004. Surface behaviour and peptide-lipid interactions of the antibiotic peptides, Maculatin and Citropin. Biochim. Biophys. Acta. 1664, 31-37.

Ambroggio, E. E., Separovic, F., Bowie, J. H., Fidelio, G. D., Bagatolli, L. A. 2005. Direct visualization of membrane leakage induced by the antibiotic peptides: maculatin, citropin, and aurein. Biophys. J. 89, 1874-1881.

Apponyi, M. A., Pukala, T. L., Brinkworth, C. S. Maselli, V. M., Bowie, J. H., Tyler' M. J., Booker, G. W, Wallace, J. C., Carver, J. A., Separovic, F., Doyle, J., Llewellyn L. E. 2004. Host-defence peptides of Australian anurans: structure, mechanism of action and evolutionary significance. Peptides 25, 1035-1054.

Balla, M. S., Bowie, J. H., Separovic, F. 2004. Solid-state NMR study of antimicrobial peptides from Australian frogs in phospholipid membranes. Eur. Biophys. J. 33, 109-116.

Bechinger, B., Lohner, K. 2006. Detergent-like actions of linear amphipathic cationic antimicrobial peptides. Biochim. Biophys. Acta 1758, 1529-1539.

Bligh, E. G., Dyer, W. J. 1959. A rapid method of total lipid extraction and purification. Can. J. Med. Sci. 37, 911-917.

Blume, A. 1979. A comparative study of the phase transitions of phospholipid bilayers and monolayers. Biochim. Biophys. Acta 557, 32-44. 
Boland, M. P., Separovic, F. 2006. Membrane interactions of antimicrobial peptides from Australian tree frogs. Biochim. Biophys. Acta 1758, 1178-1183.

Brandenburg, K., Kusumoto, S., Seydel, U. 1997. Conformational studies of synthetic lipid A analogues and partial structures by infrared spectroscopy. Biochim. Biophys. Acta 1329, 183201.

Brandenburg, K., Harris, F., Dennison, S., Seydel, U., Phoenix, D. 2002. Domain V of mcalpain shows the potential to form an oblique-orientated alpha-helix, which may modulate the enzyme's activity via interactions with anionic lipid. Eur. J. Biochem. 269, 5414-5422.

Brasseur, R. 2000. Tilted peptides: a motif for membrane destabilization (hypothesis). Mol. Membr. Biol. 17, 31-40.

Brogden, K. A. 2005. Antimicrobial peptides: pore formers or metabolic inhibitors in bacteria? Nat. Rev. Microbiol. 3, 238-250.

Bulet, P., Stocklin, R. 2005. Insect antimicrobial peptides: Structures, properties and gene regulation. Prot. Peptid. Lett. 12, 3-11.

Castro, M. S., Cilli, E. M., Fontes, W. 2006. Combinatorial synthesis and directed evolution applied to the production of alpha-helix forming antimicrobial peptides analogues. Curr. Protein Pept. Sci. 7, 473-478.

Chan, C., Burrows, L. L., Deber, C. M. 2004. Helix induction in antimicrobial peptides by alginate in biofilms. J. Biol. Chem. 279, 38749-38754.

Curtin, J., Cormican, M. 2003. Measuring Antimicrobial Activity Against Biofilm Bacteria Rev. Environ. Sci. Biotechnol. 2, 1569-1705.

Davies, J. T., Rideal, E. K. 1963. Interfacial phenomena, 2nd edn. New York: Academic Press. 
del Pozo, J. L., Patel, R. 2007. The challenge of treating biofilm-associated bacterial infection. Clin. Pharmacol. Ther. 82, 204-209.

Demel, R. A. 1974. Monolayers--description of use and interaction. Methods Enzymol. 32, $539-544$.

Dennison, S. R., Dante, S., Hauß, T., Brandenburg, K., Harris, F., Phoenix, D. A. 2005a. Investigations into the membrane interactions of m-calpain domain V. Biophys. J. 88, 30083017.

Dennison, S. R., Harris, F., Phoenix, D. A. 2005b. Are oblique orientated alpha-helices used by antimicrobial peptides for membrane invasion? Protein Pept. Lett. 12, 27-29.

Dennison, S. R., Whittaker, M., Harris, F., Phoenix, D. A. 2006. Anticancer alpha-helical peptides and structure/function relationships underpinning their interactions with tumour cell membranes. Curr. Protein Pept. Sci. 7, 487-499.

Devine, D. A., Hancock, R. E. 2002. Cationic peptides: distribution and mechanisms of resistance. Curr. Pharm. Des. 8, 703-714.

Durr, U. H. N., Sudheendra, U. S., Ramamoorthy, A. 2006. LL-37, the only human member of the cathelicidin family of antimicrobial peptides. Biochim. Biophys. Acta 1758, 14081425 .

Eisenberg, D., Weiss, R. M., Terwilliger, T. C. 1982. The helical hydrophobic moment: a measure of the amphiphilicity of a helix. Nature 299, 371-374.

Giuliani, A., Pirri, G., Nicoletto, S. F. 2007. Antimicrobial peptides: an overview of a promising class of therapeutics. Cent. Eur. J. Biol. 2, 1-33.

Hardy, N. J., Richardson, T. H., Grunfeld, F. 2006. Minimising monolayer collapse on Langmuir troughs. Colloids Surf. A Physicochem. Eng. Asp. 284-285, 202-206. 
Harris, F., Wallace, J., Phoenix, D. A. 2000. Use of hydrophobic moment plot methodology to aid the identification of oblique orientated alpha-helices. Mol. Membr. Biol. 17, 201-207.

Henzler-Wildman, K. A., Martinez, G. V., Brown, M. F., Ramamoorthy, A. 2004. Perturbation of the hydrophobic core of lipid bilayers by the human antimicrobial peptide LL-37. Biochemistry 43, 8459-8469.

Jenssen, H., Hamill, P., Hancock, R. E. W. (2006). Peptide antimicrobial agents. Clin. Microbiol. Rev. 19, 491-511.

Keller, R. C., Killian, J. A., de Kruijff, B. 1992. Anionic phospholipids are essential for alpha-helix formation of the signal peptide of prePhoE upon interaction with phospholipid vesicles. Biochemistry 31, 1672-1677.

Kuo, H. H., Chan, C., Burrows, L. L., Deber, C. M. 2007. Hydrophobic interactions in complexes of antimicrobial peptides with bacterial polysaccharides. Chem. Biol. Drug Des. 69, 405-412.

Lohner, K., Prenner, E. J. 1999. Differential scanning calorimetry and X-ray diffraction studies of the specificity of the interaction of antimicrobial peptides with membrane-mimetic systems. Biochim. Biophys. Acta 1462, 141-156.

Marcotte, I., Wegener, K. L., Lam, Y. H., Chia, B. C., de Planque, M. R., Bowie, J. H., Auger, M., Separovic, F. 2003. Interaction of antimicrobial peptides from Australian amphibians with lipid membranes. Chem. Phys. Lipids 122, 107-120.

Marr, A. K., Gooderham, W. J., Hancock, R. E. W. 2006. Antibacterial peptides for therapeutic use: obstacles and realistic outlook. Curr. Opin. Pharmacol. 6, 468-472.

Marshall, S. H., Arenas, G. 2003. Antimicrobial peptides: A natural alternative to chemical antibiotics and a potential for applied biotechnology. Electron. J. Biotechnol. 6. 1-13. 
Mookherjee, N., Hancock, R. E. W. 2007. Cationic host defence peptides: Innate immune regulatory peptides as a novel approach for treating infections. Cell. Mol. Life Sci. 64, 922933.

Nizet, V. 2007. Understanding how leading bacterial pathogens subvert innate immunity to reveal novel therapeutic targets. J. Allergy Clin. Immunol. 120, 13-22.

Quickenden, T. I., Tan, G. K. 1974. Random packing in two dimensions and the structure of monolayers. J. Colloid Interface Sci. 48, 382-393.

Rahman, M., Lins, L., Thomas-Soumarmon, A., Brasseur, R. 1997. Are Amphipathic Asymmetric Peptides Ubiquitous Structures for Membrane Destabilisation? J. Mol. Model 3, 203-215.

Ramamoorthy, A., Thennarasu, S., Lee, D. K., Tan, A., Maloy, L. 2006. Solid-state NMR investigation of the membrane-disrupting mechanism of antimicrobial peptides MSI-78 and MSI-594 derived from magainin 2 and melittin. Biophys. J. 91, 206-216.

Rodriguez-Martinez, J. M., Pascual, A. 2006. Antimicrobial resistance in bacterial biofilms. Rev. Med. Microbiol. 17, 65-75.

Ronzon, F., Desbat, B., Chauvet, J.-P., Roux, B. 2002. Penetration of a GPI-anchored protein into phospholipid monolayers spread at the air/water interface. Colloids Surf. B Biointerfaces $23,365-373$.

Sato, H., Feix, J. B. 2006. Peptide-membrane interactions and mechanisms of membrane destruction by amphipathic alpha-helical antimicrobial peptides. Biochim. Biophys. Acta $1758,1245-1256$.

Seelig, A. 1987. Local anesthetics and pressure: a comparison of dibucaine binding to lipid monolayers and bilayers. Biochim. Biophys. Acta 899, 196-204.

Sospedra, P., Espina, M., Gomara, M. J., Alsina, M. A., Haro, I., Mestres, C. 2001. Study at the Air/Water Interface of a Hepatitis A N-Acetylated and C-Amidated Synthetic Peptide 
(AcVP3(110-121)- $\mathrm{NH}_{2}$ ): II. Miscibility in Lipid Monolayers. J. Colloid Interface Sci. 244, 87-96.

Tamang, D. G., Saier, M. H. 2006. The cecropin superfamily of toxic peptides. J. Mol. Microbiol. Biotechnol. 11, 94-103.

Thomas, A., Brasseur, R. 2006. Tilted peptides: The History. Curr. Protein Pept. Sci. 7, 523527.

Todd, J. 1963. Introduction to the Constructive Theory of Functions. New York: Academic Press.

Zaiou, M. 2007. Multifunctional antimicrobial peptides: therapeutic targets in several human diseases. J. Mol. Med. 85, 317-329.

Zasloff, M. 2002. Antimicrobial peptides of multicellular organisms. Nature 415, 389-395.

Zelezetsky, I., Tossi, A. 2006. Alpha-helical antimicrobial peptides - Using a sequence template to guide structure-activity relationship studies. Biochim. Biophys. Acta 1758, 14361449. 
Table 1. Lipid composition of bacteria membranes. Table shows the molar ratios of major lipids found in the membranes of Gram-positive and Gram-negative bacteria (Lohner \& Prenner, 1999), which are represented in this study by B. subtilis and E. coli respectively.

Table 2. The compressibility moduli $\left(\mathrm{C}_{\mathrm{s}}^{-1}\right)$ of lipid monolayers at varying surface pressure (p). Values of $\mathrm{C}_{\mathrm{s}}^{-1}$ were computed using data from compression isotherms (Fig. 5) and equation 1. Monolayers were formed from either: DOPG, DOPE, CL, or lipid mixtures that corresponded to membranes of B. subtilis and E. coli respectively, all as described above

Table 3. The Gibbs free energy of mixing $\left(\Delta \mathrm{G}_{M i x}\right)$ of lipid monolayers at varying surface pressure (p). Values of $\Delta \mathrm{G}_{\text {Mix }}$ were determined for monolayers formed from lipid mixtures that corresponded to membranes of B. subtilis and E. coli respectively. These parameters varied with surface pressures and the presence $(+\mathrm{VP} 1)$ or absence $(-\mathrm{VP} 1)$ of VP1. For $B$. subtilis membrane mimics, $\Delta \mathrm{G}_{\text {Mix }}$ was changed from positive to negative values by the presence of VP1, indicating that the peptide rendered these monolayers thermodynamically stable. In contrast, the presence of VP1 changed $\Delta \mathrm{G}_{\text {Mix }}$ from negative values to positive values for E. coli membrane mimics, indicating that the peptide rendered these monolayers thermodynamically unstable. $\Delta \mathrm{G}_{M i x}$ was computed using data from the compression isotherms of Fig. 5 and equation 2, all as described above.

Table 4. The interaction parameter (a) and enthalpy of mixing $(\Delta \mathrm{H})$ of lipid monolayers at varying surface pressure $(\mathrm{p})$. Values of a and $\Delta \mathrm{H}$ were determined for monolayers formed from lipid mixtures that corresponded to membranes of B. subtilis and E. coli respectively. Values for these parameters were computed either in the presence (+VP1) or absence (-VP1) of VP1 using data from compression isotherms (Fig. 5) in conjunction with equations 2, 3, and 4 respectively, all as described above. 
Table 1. Lipid composition of bacteria membranes.

\begin{tabular}{|c|c|c|c|}
\hline Bacterium & CL & DOPG & DOPE \\
\hline B. subtilis & 4.7 & 2.9 & 1.0 \\
\hline E. coli & 2.00 & 1.00 & 13.67 \\
\hline
\end{tabular}


Table 2. The compressibility moduli $\left(\mathrm{C}_{\mathrm{s}}^{-1}\right)$ of lipid monolayers at varying surface pressure (p).

\begin{tabular}{|c|c|c|c|c|c|}
\hline \multirow{2}{*}{$\begin{array}{c}\text { Pressure } \\
\mathbf{p}\left(\mathbf{m N ~ m}^{-1}\right)\end{array}$} & \multicolumn{5}{|c|}{$\mathbf{C}_{\mathbf{s}}^{-1}\left(\mathbf{m N ~ m}^{-1}\right)$} \\
& $\mathbf{6 L}$ & DOPG & DOPE & B. subtilis & E. coli \\
\cline { 2 - 6 } & 5.717 & 8.22 & 6.06 & 8.37 & 7.65 \\
\hline $\mathbf{5}$ & 11.03 & 13.45 & 13.01 & 16.72 & 13.36 \\
\hline $\mathbf{1 0}$ & 40.41 & 18.95 & 19.89 & 17.35 & 18.12 \\
\hline $\mathbf{1 5}$ & 72.89 & 24.51 & 25.80 & 22.01 & 25.71 \\
\hline $\mathbf{2 0}$ & & & & & \\
\hline
\end{tabular}


Table 3. The Gibbs free energy of mixing $\left(\Delta G_{M i x}\right)$ of lipid monolayers at varying surface pressure (p).

\begin{tabular}{|c|c|c|c|c|}
\hline \multirow[t]{3}{*}{$\begin{array}{l}\text { Surface Pressure } \\
\qquad\left(\mathrm{mN} \mathrm{m}^{-1}\right)\end{array}$} & \multicolumn{4}{|c|}{$\begin{array}{c}\Delta \mathrm{G}_{M i x} \\
\left(\mathbf{J} \mathbf{m o l}^{-\mathbf{1}}\right)\end{array}$} \\
\hline & \multicolumn{2}{|c|}{ B. subtilis } & \multicolumn{2}{|c|}{ E. coli } \\
\hline & -VP1 & $+V P 1$ & -VP1 & +VP1 \\
\hline 5 & 0.91 & -170.55 & -16.17 & 3.13 \\
\hline 10 & 120.76 & -298.35 & -40.48 & 23.42 \\
\hline 15 & 365.93 & -373.10 & -53.11 & 36.85 \\
\hline
\end{tabular}


Table 4. The interaction parameter (a) and enthalpy of mixing $(\Delta H)$ of lipid monolayers at varying surface pressure $(p)$.

\begin{tabular}{|c|c|c|c|c|c|c|c|c|}
\hline \multirow[t]{3}{*}{$\begin{array}{l}\text { Pressure } \\
\left(\mathrm{mNm}^{-1}\right)\end{array}$} & \multicolumn{4}{|c|}{$\mathrm{a}$} & \multicolumn{4}{|c|}{$\begin{array}{c}\Delta \mathrm{H} \\
\left(\mathrm{J} \mathrm{mol}^{-1}\right)\end{array}$} \\
\hline & \multicolumn{2}{|c|}{ B. subtilis } & \multicolumn{2}{|c|}{ E. coli } & \multicolumn{2}{|c|}{ B. subtilis } & \multicolumn{2}{|c|}{ E. coli } \\
\hline & -VP1 & $+\mathrm{VP} 1$ & -VP1 & $+\mathrm{VP} 1$ & -VP1 & $+\mathrm{VP} 1$ & $-\mathrm{VP} 1$ & $+\mathrm{VP} 1$ \\
\hline 5 & 0.04 & -7.5 & -1.6 & 0.3 & 49.24 & -9182.4 & -1984.0 & 385.0 \\
\hline 10 & 5.3 & -13.1 & -4.1 & 2.3 & 6502.1 & -8031.6 & -4966.9 & 2873.8 \\
\hline 15 & 11.2 & -16.4 & -5.3 & 3.7 & 13627.0 & -6695.4 & -6517.3 & 4521.4 \\
\hline
\end{tabular}




\section{FIGURE LEGENDS}

Fig. 1A Analysis of (A) VP1 (GTAMRILGGVI), (B) citropin 1.1 (GLFDVIKKVASVIGGL$\mathrm{NH}_{2}$ ) and $(\mathrm{C})$ aurein 1.2 (GLFDIIKKIAESF-NH ) for gradients in hydrophobicity using the normalised consensus hydrophobicity scale of (Eisenberg et al., 1982) and a seven residue window. Each peptide exhibited an overall progressive increase in hydrophobicity along it sequence, which in the case of VP1 and citropin 1.1 progressed from the $\mathrm{N}$-terminus to the Cterminus but in the reverse direction in the case of aurein 1.2. Fig. 1B. The sequences of VP1, citropin 1.1 and aurein 1.2 represented as two-dimensional axial projections. The $\alpha$-helix of each peptide possessed a hydrophilic face, composed of charged and polar residues (circled) and multiple gycines, and a wide hydrophobic face formed from bulky amino residues. Fig. 1 was adapted from Dennison et al., (2005b).

Fig.. 2A. The viability of B. subtilis (dotted) and E. coli (solid) was measured by analysing the CFU's as described in the methods. Data are represented as percentage death rate in the presence of VP1 (3 mM). At these levels, the peptide is bacteriocidal, achieving a $100 \%$ death rate after 4 hours in the case of B. subtilis and after 1 hour in the case of E. coli. The percentage death rate was determined by comparison with identical non-inoculated control cultures, all as described above. Fig. 2B. Laser scanning confocal images of E. coli and B. subtilis formed on BD falcon culture slides and stained with propidium iodide; Image A light microscope image at $\times 400, \mathrm{~B}-$ not treated, $\mathrm{C}-500 \mu \mathrm{M}$ VP1 and D - $4 \mathrm{mM}$ VP1.

Fig. 3. Shows FTIR analysis of VP1 effects on the phase transition properties of Vesicles formed from bacterial lipid extracts. In the absence of VP1, membranes of B. subtilis ( $\square$, Fig. 3A) and E. coli ( 4 , Fig. 3B) showed similar lipid phase transition properties going from the gel phase to the liquid crystalline phase over the range 25 to $40^{\circ} \mathrm{C}$ with a concomitant increase in membrane fluidity as indicated by the rise in wavenumber from circa $2851.5 \mathrm{~cm}^{-1}$ to $2853.5 \mathrm{~cm}^{-1}$. In each case, the presence of VP1 caused no apparent shift in this temperature range but induced a significant change in membrane fluidity. The fluidity of B. subtilis membranes underwent a significant increase, as indicated by a general rise in wavenumber of between 0.5 to $1.0 \mathrm{~cm}^{-1}$ ( $\boldsymbol{\square}$, Fig.3A). In contrast, the fluidity of $E$. coli membranes underwent a significant decrease, as indicated by a general fall in wavenumber of between 0.5 to 1.0 $\mathrm{cm}^{-1}$ (O, Fig. 3B). 
Fig. 4. Shows the time course of VP1 with lipid monolayers at an initial surface pressure of $330 \mathrm{mN} \mathrm{m}^{-1}$. These monolayers were formed from whole lipid extract from B. subtilis membranes (grey) and synthetic lipid mimics of these membranes (black) respectively (Fig. 4A). Fig. 4B monolayers were formed from whole lipid extract from E. coli membranes (grey) and synthetic lipid mimics of these membranes (black). VP1 was introduced into the subphase to give a final concentration $20 \mu \mathrm{M}$ and changes in monolayer surface pressure recorded as a function of time, all as described in the methods.

Fig. 5. Compression isotherm analysis of lipid monolayers. Fig. 5A and Fig. 5B show isotherms derived from lipid mixtures that corresponded to membranes of B. subtilis and $E$. coli in the absence and presence of VP1 at a final subphase concentration of $20 \mu \mathrm{M}$, respectively. Fig. 5C and Fig.5D show isotherms derived from (a) DOPE, (b) DOPG and (c) CL in the absence and presence of VP1 at a final subphase concentration of $20 \mu \mathrm{M}$, respectively. The variation of surface pressure with area per lipid molecule was monitored as monolayers were compressed, all as described above.

Fig. 6. Compression isotherms were derived from monolayers formed from CL and PG at varying ratios in the absence $(\diamond)$ and presence $(\boldsymbol{\square})$ of VP1 at a final subphase concentration of $20 \mu \mathrm{M}$. The variation of surface pressure with area per lipid molecule was monitored as monolayers were compressed, all as described above, and these data used to determine $\Delta G_{\text {Mix }}$ using equation 2, which was then plotted as a function of the monolayer CL:PG molar ratio.

Fig. 7. Compression isotherms were derived from monolayers which formed from CL and PG at a ratio of 1.6:1 (Table 1) corresponding to that in B. subtilis. Isotherms were obtained with varying levels of PE, in the absence $(\bullet)$ and presence $(\boldsymbol{\square})$ of VP1 at a final subphase concentration of $20 \mu \mathrm{M}$. The variation of surface pressure with area per lipid molecule was monitored as monolayers were compressed, all as described above, and these data used to determine $\Delta \mathrm{G}_{\text {Mix }}$ using equation 2 , which was then plotted as a function of the monolayer PE molar ratio.

Fig. 8. Compression isotherms were derived from monolayers which formed from CL and PG at a ratio of 2:1 (Table 1) corresponding to that in E. coli. Isotherms were also obtained with varying levels of PE, in the absence $(\bullet)$ and presence $(\boldsymbol{\square})$ of VP1 at a final subphase 
concentration of $20 \mu \mathrm{M}$. The variation of surface pressure with area per lipid molecule was monitored as monolayers were compressed, all as described above, and these data used to determine $\Delta \mathrm{G}_{\text {Mix }}$ using equation 2 , which was then plotted as a function of the monolayer PE molar ratio. 
Fig. 1A

A
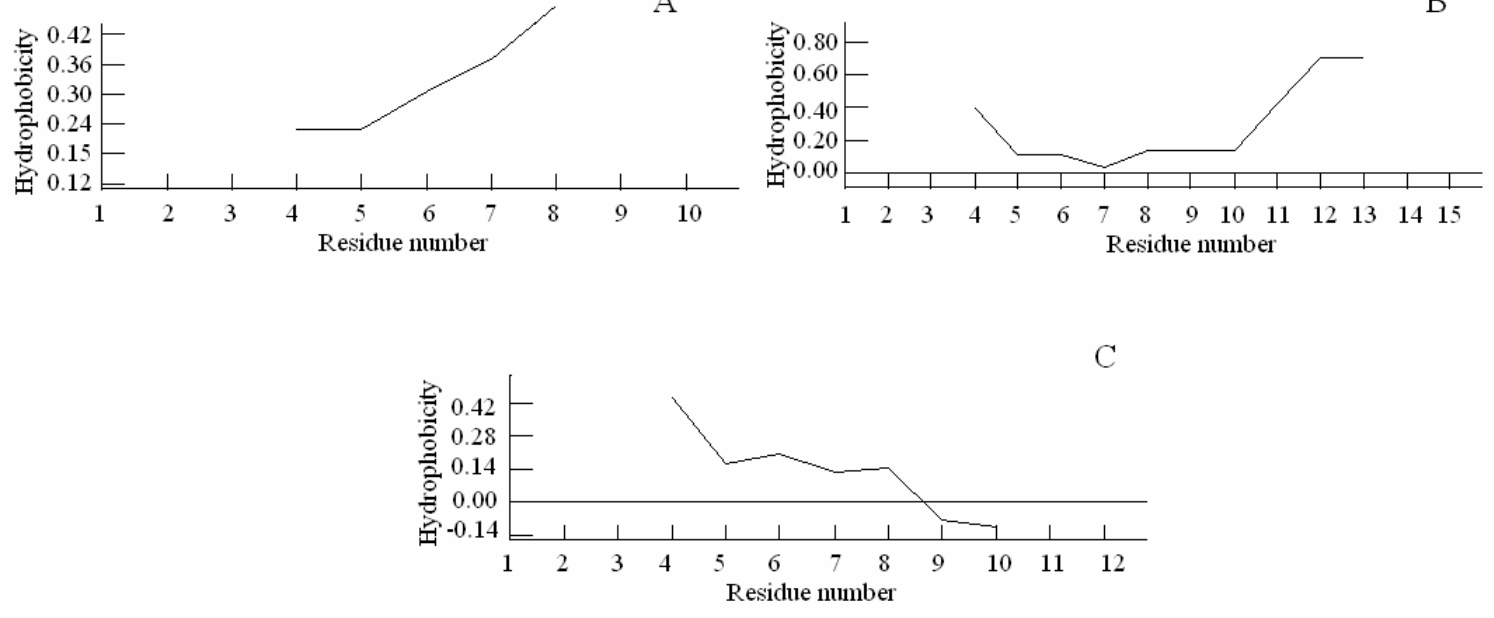

Fig. 1B

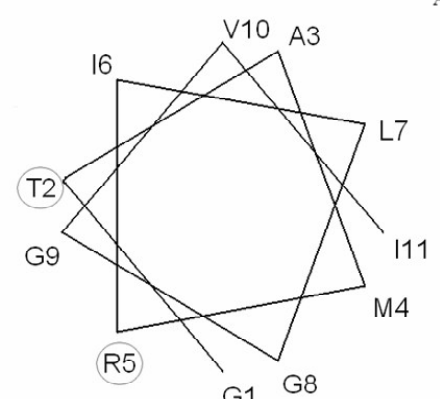

A
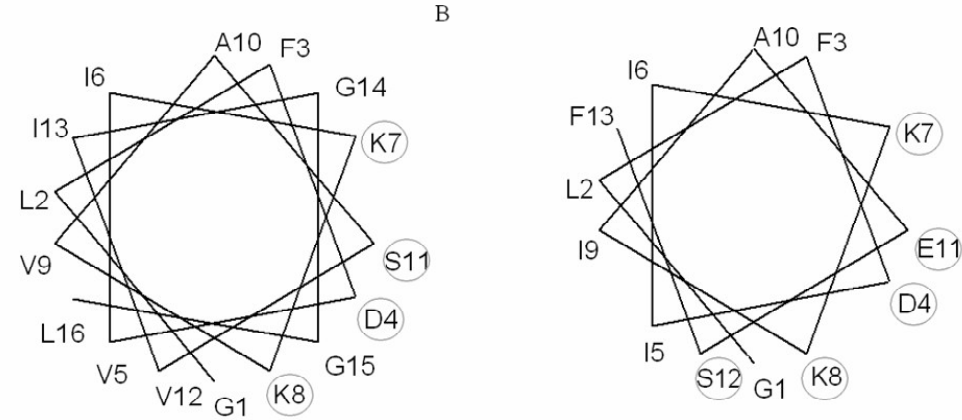
Fig. 2

Fig. 2A

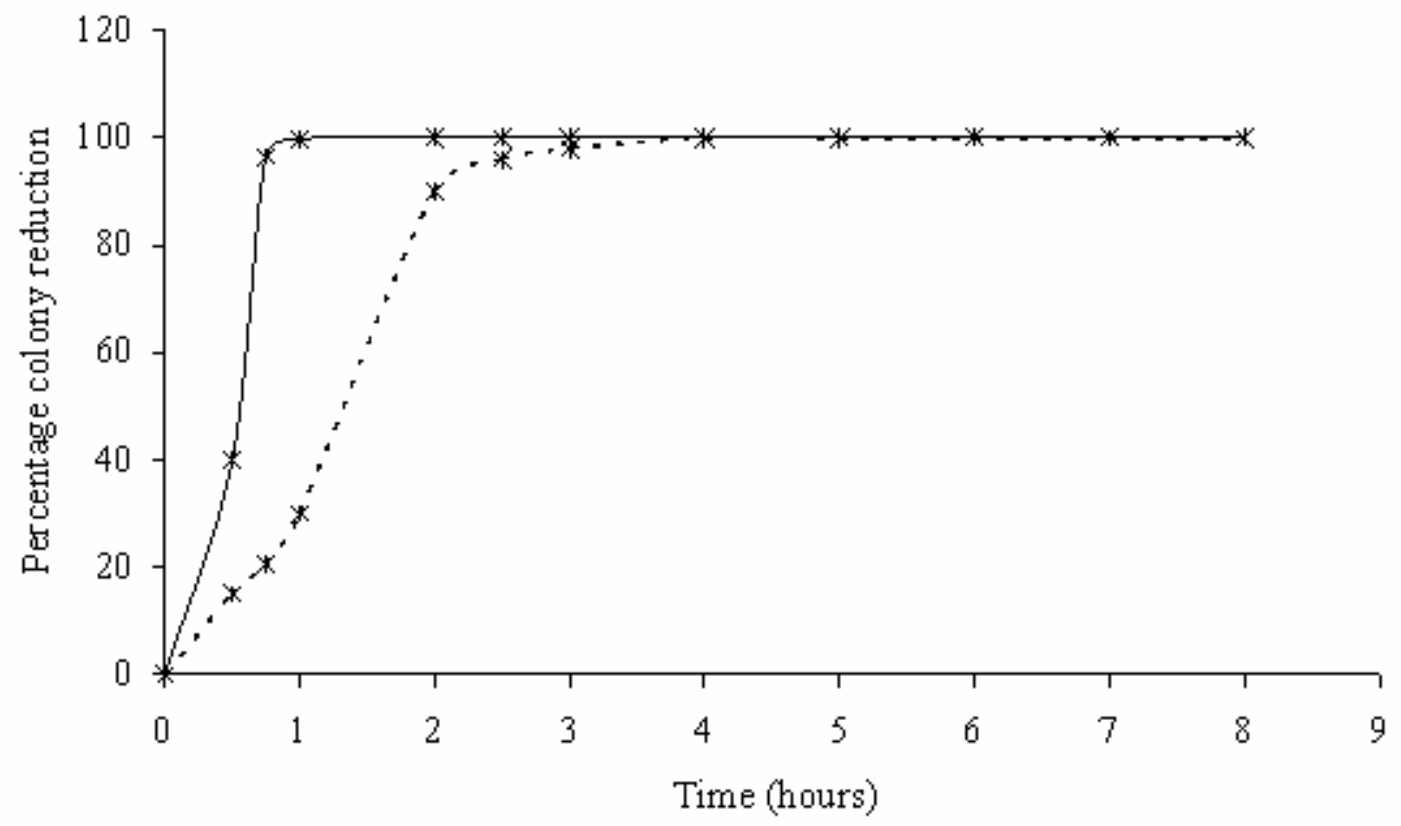

Fig. 2B

A

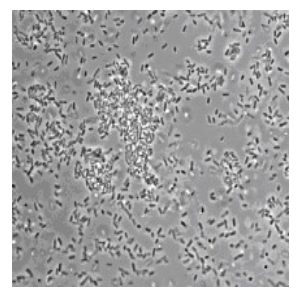

E. coli

A

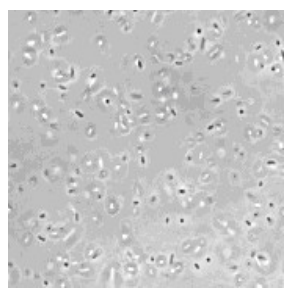

B. subtilis
B

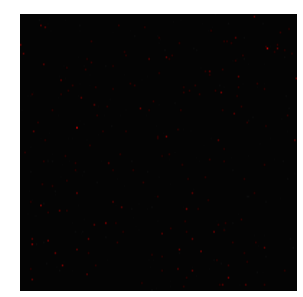

C

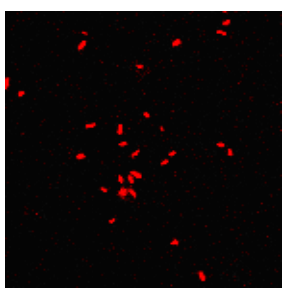

D

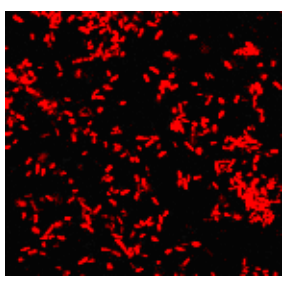

C

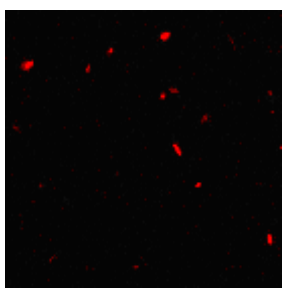

D

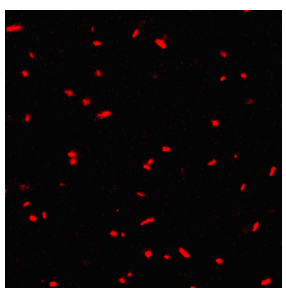


Fig. 3

A
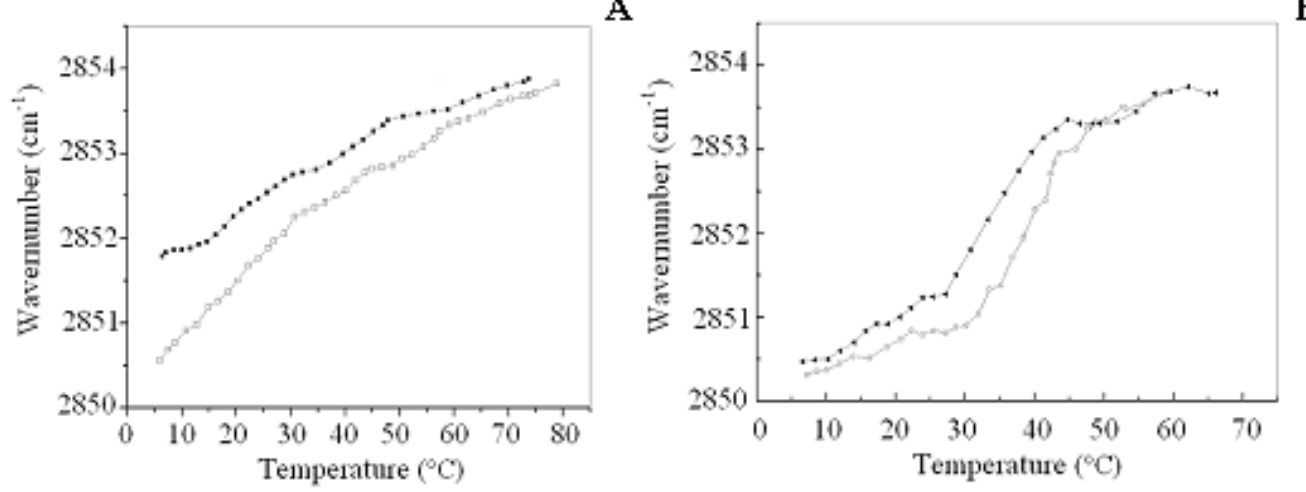
Fig. 4A

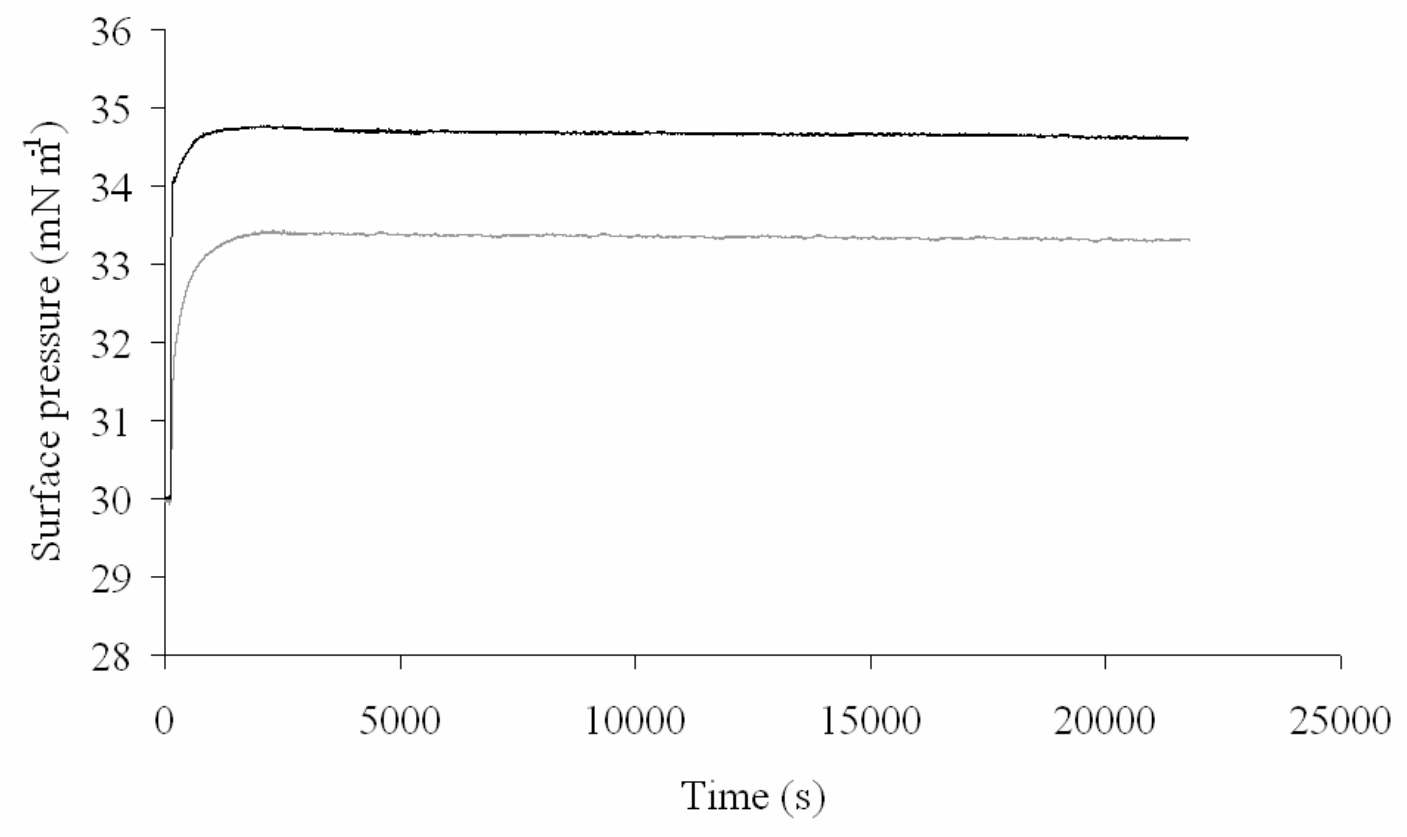

Fig. 4B

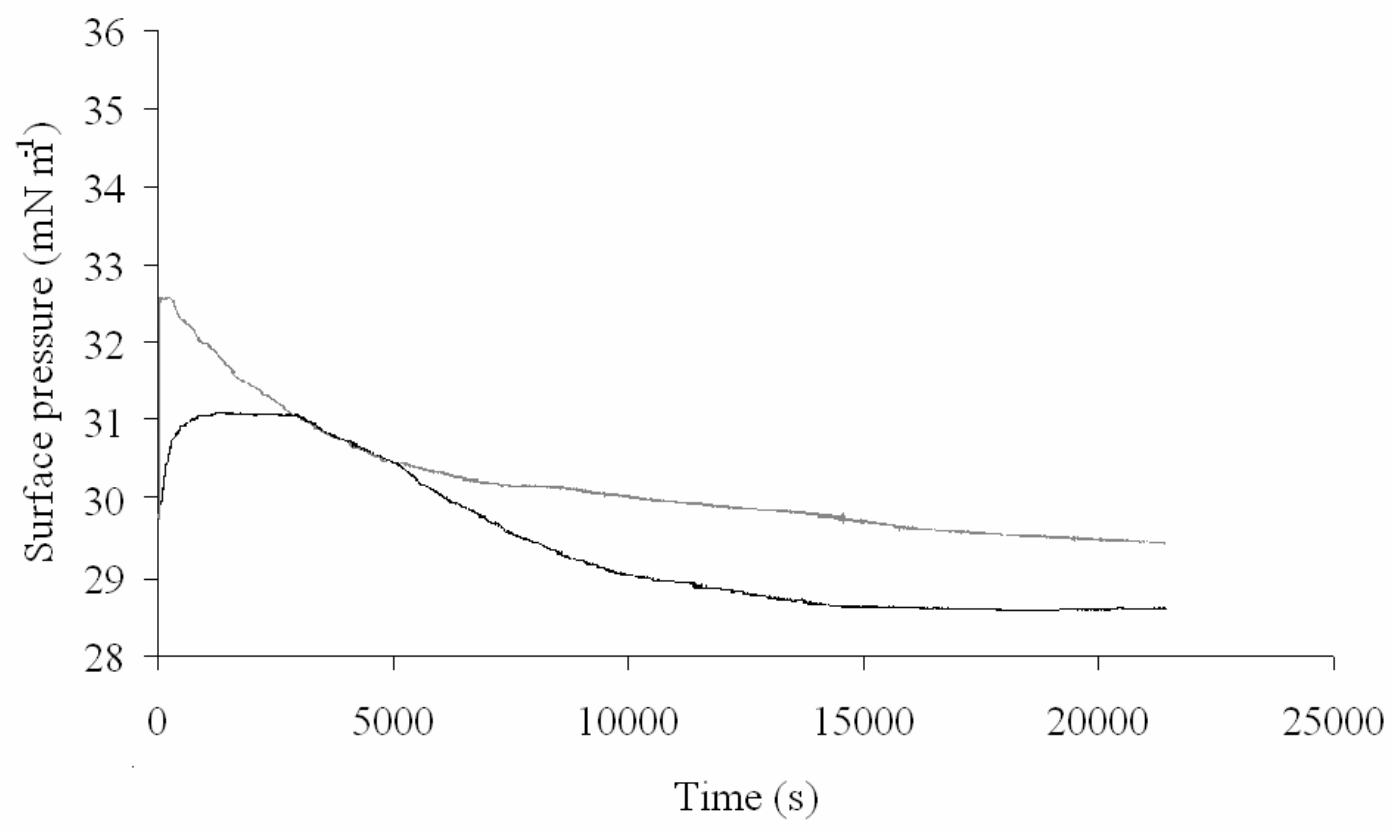


Fig. 5

A

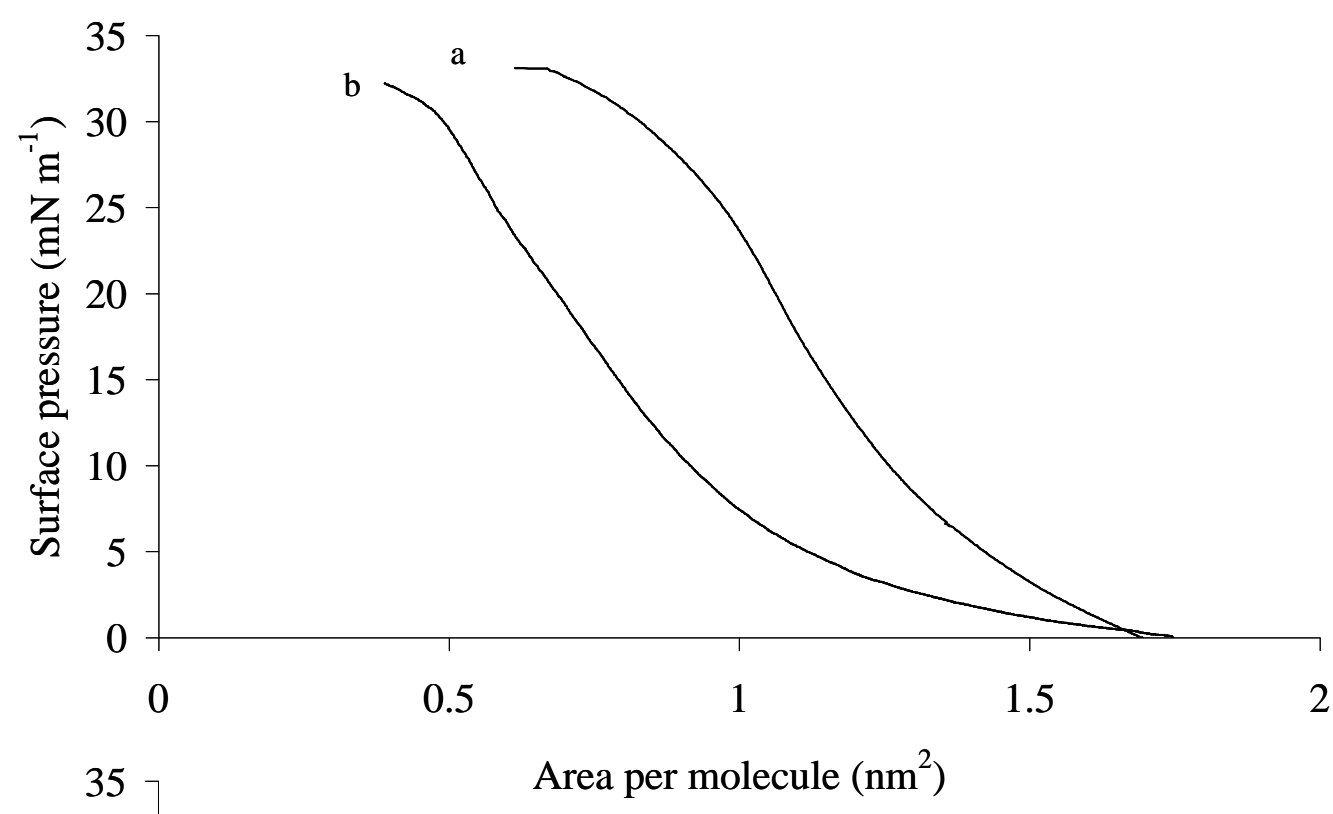

B

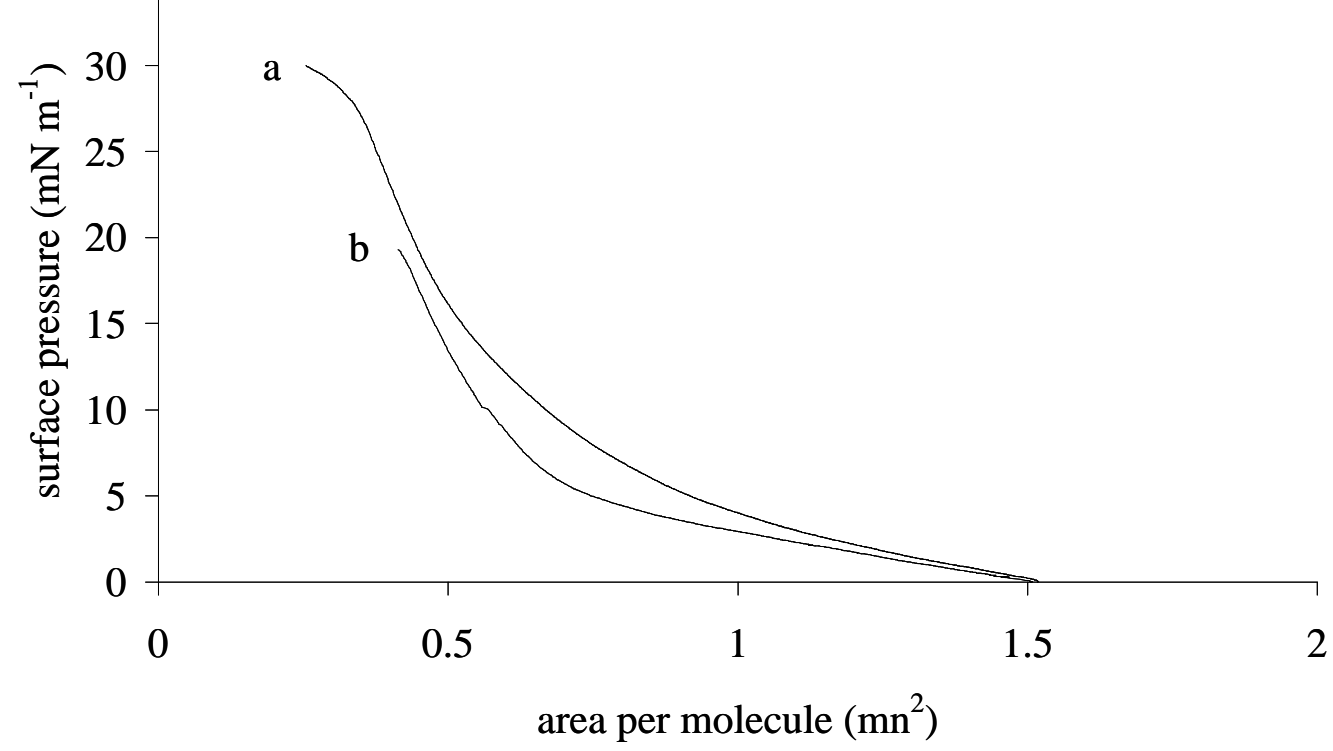


C

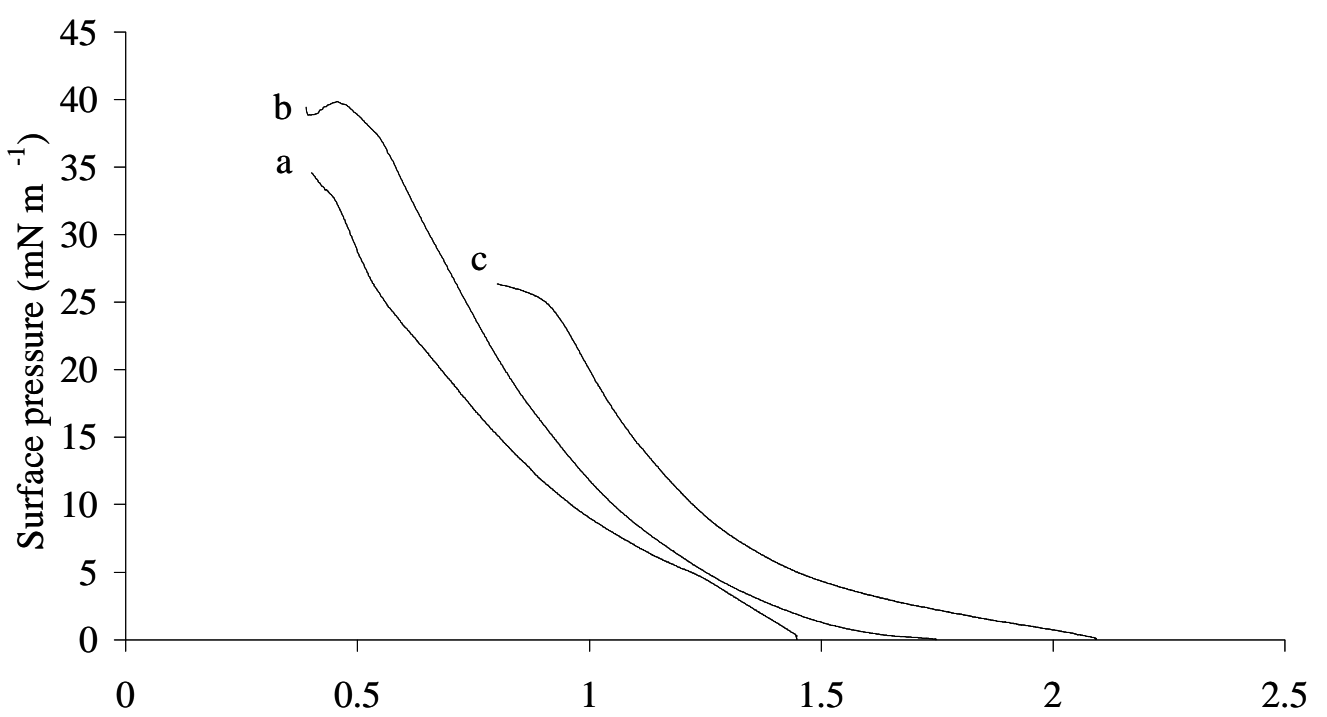

Area per molecule $\left(\mathrm{nm}^{2}\right)$

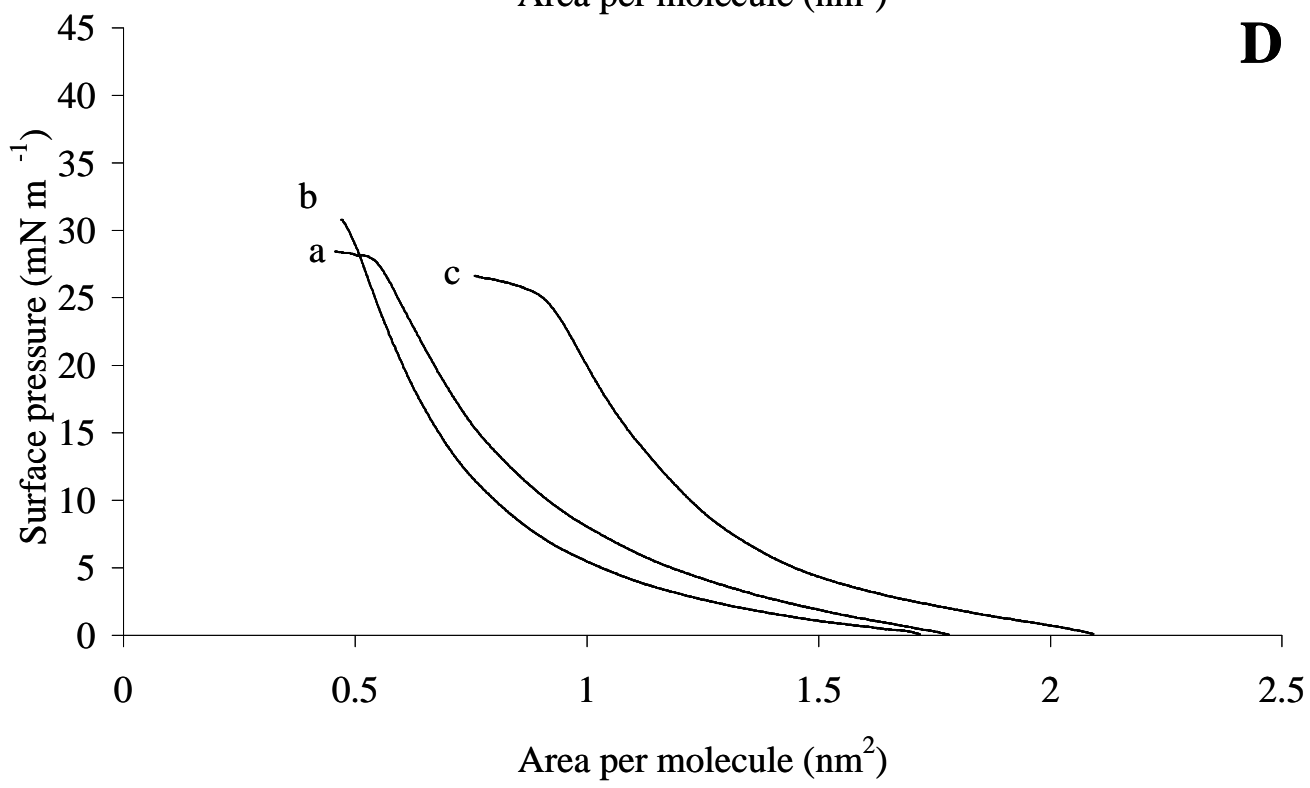

Fig. 5 
Fig. 6

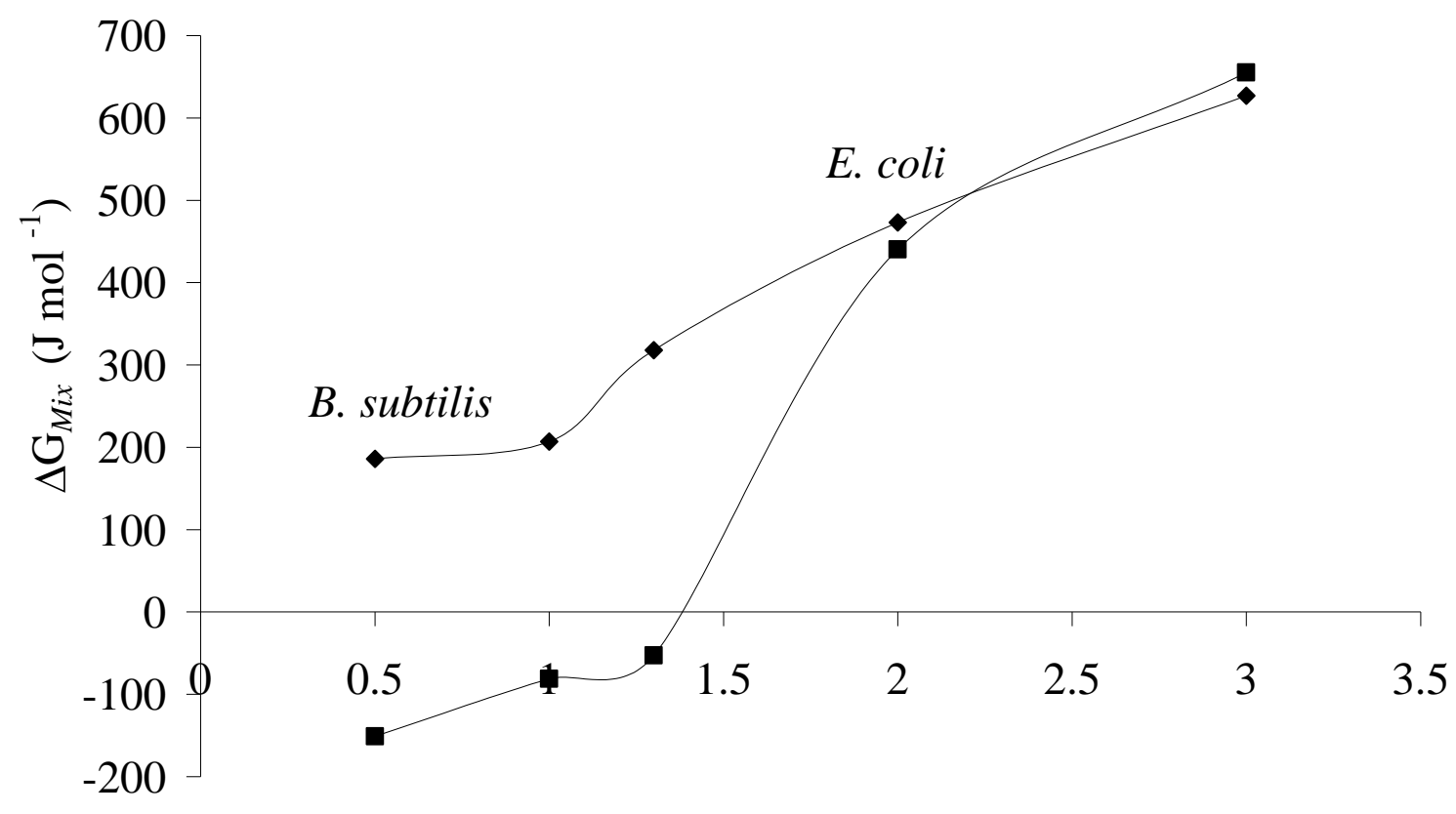

Ratio CL:PG 
Fig. 7

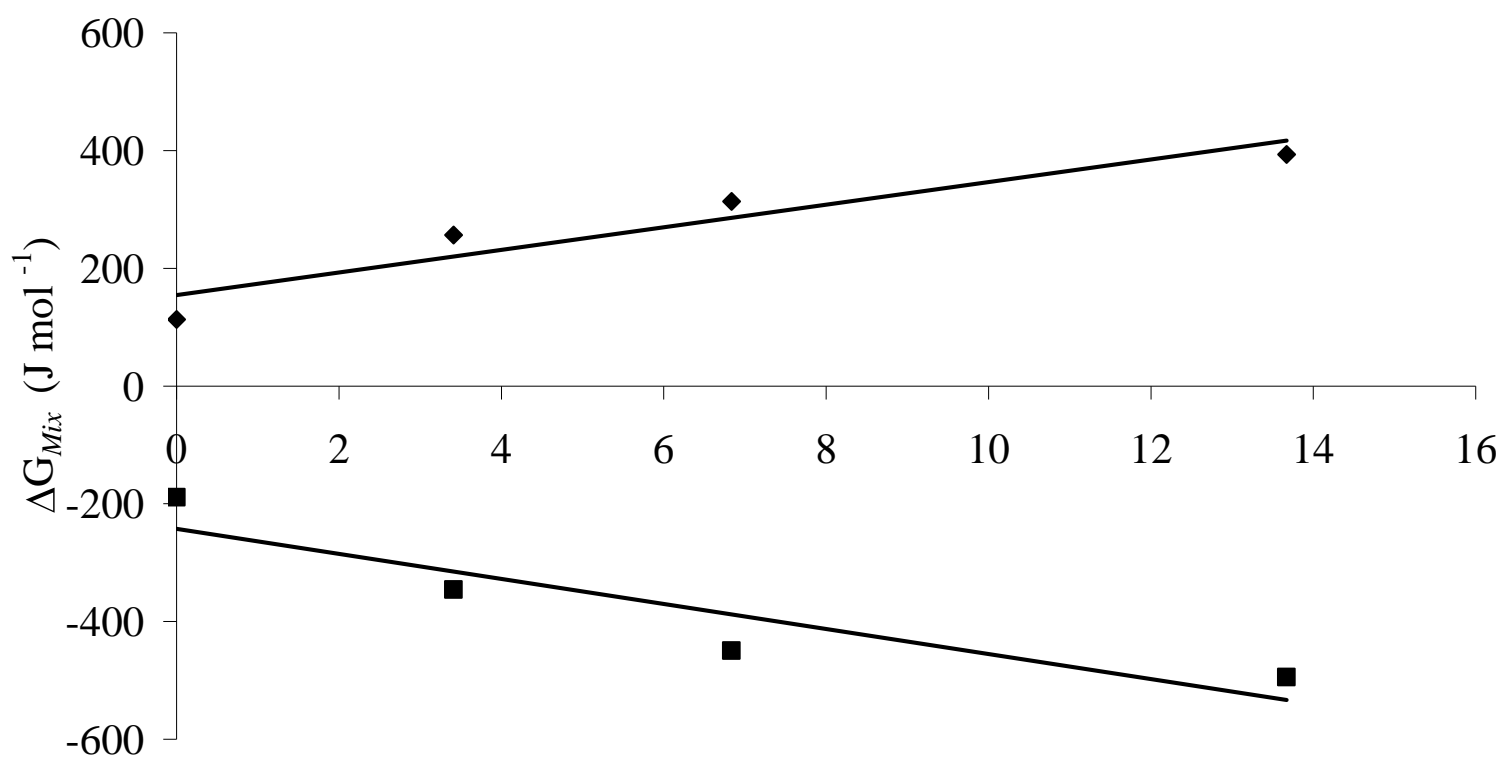

Ratio of PE to other monolayer lipids

(CL:PG held constant at 1.6:1) 
Fig. 8

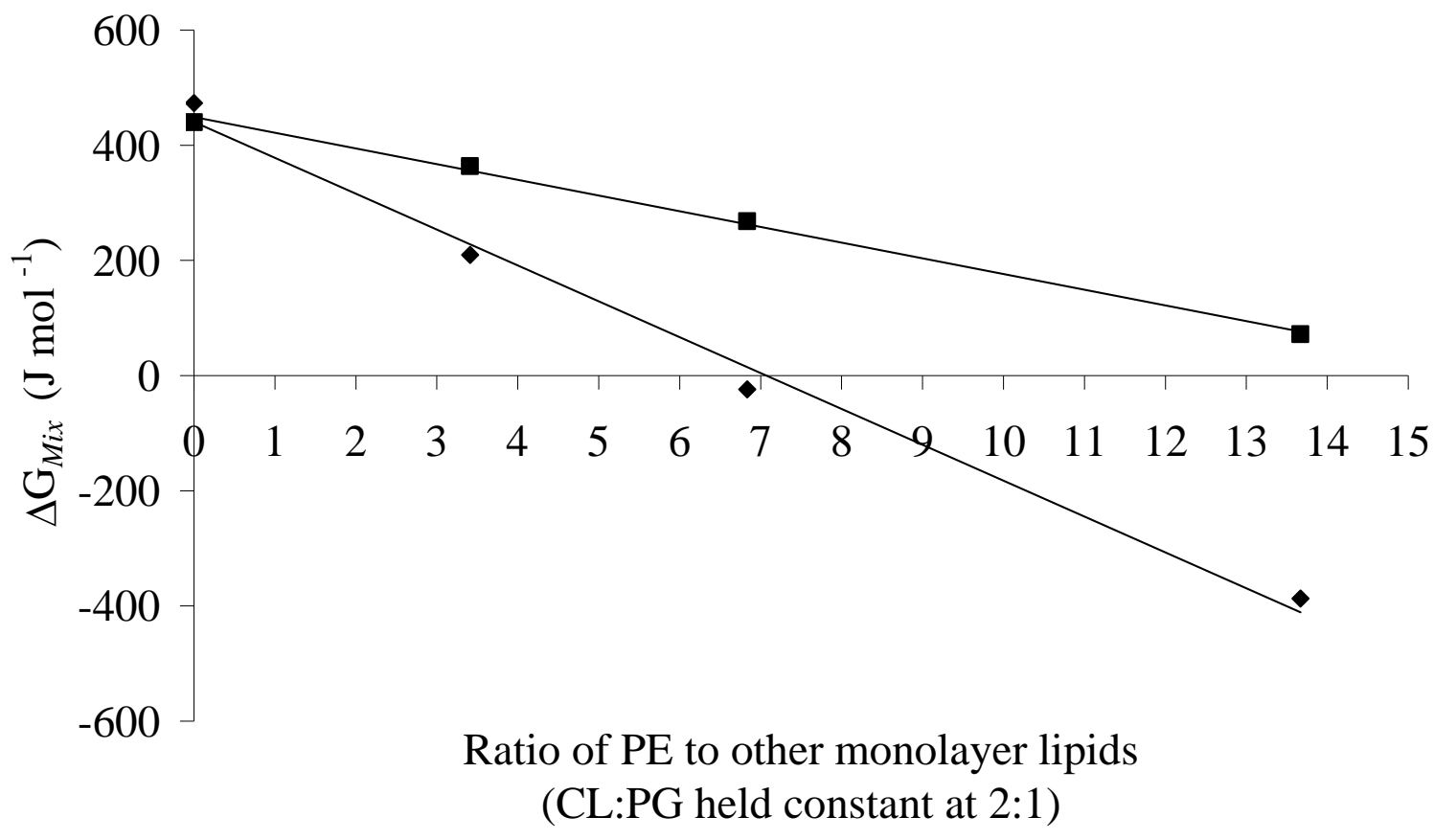

